San Jose State University

SJSU ScholarWorks

Master's Theses

Master's Theses and Graduate Research

1991

\title{
Reducing risk factors for heart disease by telephone follow-up after hospitalization
}

Barbara B. Lustig

San Jose State University

Follow this and additional works at: https://scholarworks.sjsu.edu/etd_theses

\section{Recommended Citation}

Lustig, Barbara B., "Reducing risk factors for heart disease by telephone follow-up after hospitalization" (1991). Master's Theses. 85.

DOI: https://doi.org/10.31979/etd.2c2x-dq63

https://scholarworks.sjsu.edu/etd_theses/85

This Thesis is brought to you for free and open access by the Master's Theses and Graduate Research at SJSU ScholarWorks. It has been accepted for inclusion in Master's Theses by an authorized administrator of SJSU ScholarWorks. For more information, please contact scholarworks@sjsu.edu. 


\section{INFORMATION TO USERS}

This manuscript has been reproduced from the microfilm master. UMI films the text directly from the original or copy submitted. Thus, some thesis and dissertation copies are in typewriter face, while others may be from any type of computer printer.

The quality of this reproduction is dependent upon the quality of the copy submitted. Broken or indistinct print, colored or poor quality illustrations and photographs, print bleedthrough, substandard margins, and improper alignment can adversely affect reproduction.

In the unlikely event that the author did not send UMI a complete manuscript and there are missing pages, these will be noted. Also, if unauthorized copyright material had to be removed, a note will indicate the deletion.

Oversize materials (e.g., maps, drawings, charts) are reproduced by sectioning the original, beginning at the upper left-hand corner and continuing from left to right in equal sections with small overlaps. Each original is also photographed in one exposure and is included in reduced form at the back of the book.

Photographs included in the original manuscript have been reproduced xerographically in this copy. Higher quality $6 " \mathrm{x} 9$ " black and white photographic prints are available for any photographs or illustrations appearing in this copy for an additional charge. Contact UMI directly to order.

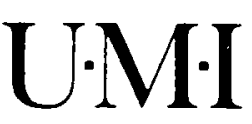

University Microfılms International

A Bell \& Howell Information Company

300 North Zeeb Road. Ann Arbor. MI 48106-1346 USA

313/761-4700 800:521-0600 
Order Number 1344281

Reducing risk factors for heart disease by telephone follow-up after hospitalization

Lustig, Barbara B., M.S.

San Jose State University, 1991 

REDUCING RISK FACTORS FOR HEART DISEASE BY TELEPHONE FOLLOW-UP AFTER HOSPITALIZATION

\author{
A Thesis \\ Presented to \\ The Faculty of the Department of Nursing \\ San Jose State University \\ In Partial Fulfillment \\ of the Requirements for the Degree \\ Master of Science
}

By

Barbara B. Lustig

August, 1991 
APPROYED FOR THE DEPARTMENT OF NURSING Sharan Uabl,

Sharon Wahl, M.S.N., R.N.

Aesry W. dhiller

Terry Millof, M.S.N., R.N.

Ann P.Poorden

Ann Doordan, M.S.N., R.N.

APPROVED FOR THE UNIVERSITY

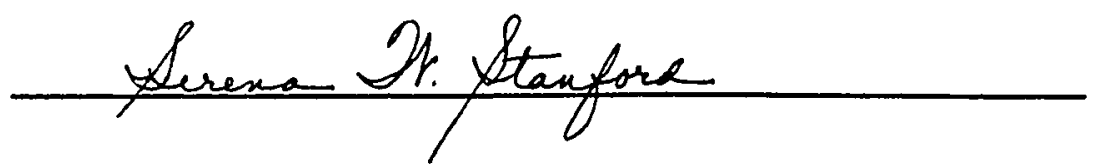




\section{DEDICATION}

To my wonderful children:

\section{Gregg, Susan, Glenn,}

Gordon, Julie, Gary and Fawn

who never stopped believing in me

and forced me to believe in myself. 


\section{ACKNOWLEDGEMENTS}

To my advisor, Sharon Wahl,

for her assistance and support;

to Beth Noland, RN, and Carol Graham, RN,

who turned the dream into a reality;

to all the Kaiser health plan members and employees

who assisted me and provided new ideas along the way;

and especially to my friend, David Buchanan M.D., for his continuing encouragement and advice. 


\title{
ABSTRACT \\ REDUCING RISK FACTORS FOR HEART DISEASE BY TELEPHONE FOLLOW-UP AFTER HOSPITALIZATION
}

\author{
By Barbara B. Lustig
}

This study investigated the effects of telephone follow-up as an intervention for reducing risk factors in patients with unstable angina after hospitalization. The role of cardiac educator nurse (CEN) was introduced at the medical facility where the study took place. The CEN provided telephone follow-up to patients after hospital discharge. Using Pender's health promotion model as the conceptual framework, patients' predisposition to changing behaviors was explored in 10 areas. Changes in behaviors were measured through intake and follow-up questionnaires developed for the study. As a result of the telephone intervention 7 subjects in the experimental group who returned questionnaires reported an increased sense of empowerment over their bodies and general feelings of well being. These results supported the need for research and development of programs incorporating health promotion and health protection services. Patients and staff were enthusiastic at the conclusion of the study, and the position of CEN was funded by the hospital administration. 


\section{TABLE OF CONTENTS}

\section{Page}

LIST OF TABLES $\ldots \ldots \ldots \ldots \ldots \ldots \ldots \ldots \ldots \ldots \ldots \ldots \ldots \ldots \ldots \ldots$ viii

LIST OF FIGURES $\ldots \ldots \ldots \ldots \ldots \ldots \ldots \ldots \ldots \ldots \ldots \ldots \ldots \ldots \ldots \ldots$ ix

\section{Chapter}

1. INTRODUCTION $\ldots \ldots \ldots \ldots \ldots \ldots \ldots \ldots \ldots \ldots \ldots \ldots \ldots$

Statement of the Problem $\ldots \ldots \ldots \ldots \ldots \ldots \ldots \ldots \ldots, 2$

Null Hypothesis $\ldots \ldots \ldots \ldots \ldots \ldots \ldots \ldots \ldots \ldots \ldots, 4$

Alternative Hypothesis . . . . . . . . . . . . . . 4

Purpose and Need $\ldots \ldots \ldots \ldots \ldots \ldots \ldots \ldots \ldots \ldots \ldots \ldots \ldots$

Definitions $\ldots \ldots \ldots \ldots \ldots \ldots \ldots \ldots \ldots \ldots \ldots \ldots \ldots \ldots \ldots$

Sample and Setting $\ldots \ldots \ldots \ldots \ldots \ldots \ldots \ldots \ldots \ldots \ldots \ldots \ldots$

Data Collection ......................... 8

Research Design $\ldots \ldots \ldots \ldots \ldots \ldots \ldots \ldots \ldots \ldots \ldots .9$

2. CONCEPTUAL FRAMEWORK AND

REVIEW OF THE LITERATURE $\ldots \ldots \ldots \ldots \ldots \ldots \ldots, 10$

Health Promotion Model $\ldots \ldots \ldots \ldots \ldots \ldots \ldots \ldots \ldots, 10$

Literature Review . .................... 15

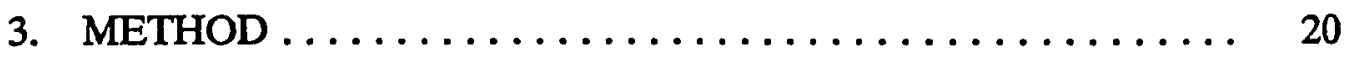

Introduction $\ldots \ldots \ldots \ldots \ldots \ldots \ldots \ldots \ldots \ldots \ldots, 20$

Subjects $\ldots \ldots \ldots \ldots \ldots \ldots \ldots \ldots \ldots \ldots \ldots \ldots \ldots, 20$

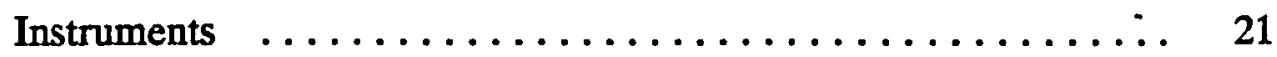




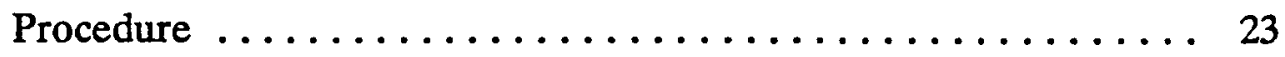

4. DATA ANALYSIS AND INTERPRETATION ......... 25

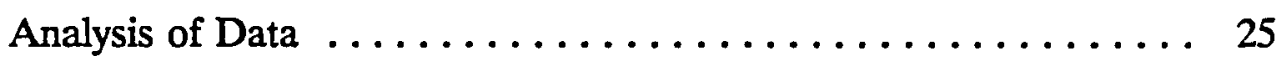

5. CONCLUSIONS AND RECOMMENDATIONS $\ldots \ldots \ldots \ldots, 32$

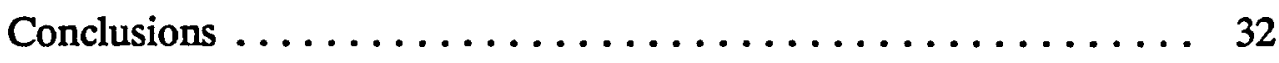

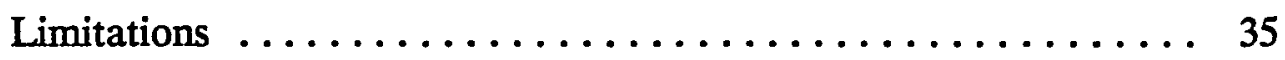

Recommendations $\ldots \ldots \ldots \ldots \ldots \ldots \ldots \ldots \ldots \ldots \ldots \ldots$

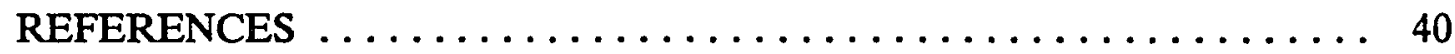

\section{APPENDICES}

A. Intake Questionnaire $\ldots \ldots \ldots \ldots \ldots \ldots \ldots \ldots \ldots \ldots$

B. Follow-up Questionnaire $\ldots \ldots \ldots \ldots \ldots \ldots \ldots \ldots, 51$

C. Photography Consent $\ldots \ldots \ldots \ldots \ldots \ldots \ldots \ldots \ldots$

D. Patient Progress Record $\ldots \ldots \ldots \ldots \ldots \ldots \ldots \ldots$

E. Project Proposal Review $\ldots \ldots \ldots \ldots \ldots \ldots \ldots \ldots . \ldots 3$

F. Consent Forms $\ldots \ldots \ldots \ldots \ldots \ldots \ldots \ldots \ldots \ldots$

Request for Project Approval ............. 66

Consent from Kaiser Permanente . . . . . . . . . . 67

Consent from SJSU $\ldots \ldots \ldots \ldots \ldots \ldots \ldots \ldots, 68$

G. Patient Consent Form $\ldots \ldots \ldots \ldots \ldots \ldots \ldots$

H. Cardiac Education Program .............. 71

I. Telephone Protocol $\ldots \ldots \ldots \ldots \ldots \ldots \ldots \ldots \ldots, 73$ 


\section{LIST OF TABLES}

Page

Table

1. Demographic Characteristics of Original Cohort .......... 26

2. Demographic Characteristics of Cohort

Returning Questionnaires $\ldots \ldots \ldots \ldots \ldots \ldots \ldots \ldots \ldots$

2. Comparison of Changes on 10 Indicators

Between Experimental and Control Group ........... 29 


\section{LIST OF FIGURES}

Page

Figure 1.

1. Health Promotion Model .................. 11 


\section{Chapter 1}

\section{INTRODUCTION}

Cardiac nurses are in a unique position to assist patients hospitalized with coronary artery disease in behavior modifications which may lessen the risk for future cardiac events. Although patients are encouraged to make lifestyle changes during their hospital stay, this is rarely achieved (Briody, 1984). The emphasis on teaching information, rather than changing attitudes and perceptions, has proven to be ineffective. Briody (1984) cited a study by Kok and others which included 1,951 Dutch adults, which Briody felt was applicable to Americans. Kok, Matroos, and vanden Ban (1982) concluded that the target group exhibited a distorted perception of the healthfulness of its own lifestyle and unfavorable attitudes toward modifying existing smoking patterns, eating habits, and physical activity. Kok et al. recommended that both affective and cognitive domains of learning be targeted in order to motivate behavioral changes (Briody, 1984). This presents a challenge to health care providers who recognize the need for intervention but who do not have the time or resources to provide the type of learning which is required.

Patients with unstable angina, admitted to the urban hospital where the study was conducted, are initially evaluated and treated by physicians. They are placed in a monitored unit for surveillance and drug therapy, given noninvasive tests to determine the severity of their disorders (treadmill test, echocardiogram, or electrocardiogram), and are then either sent to another facility for cardiac catheterization or discharged home.

During the short hospital stay, staff nurses instruct these patients on risk factors leading to heart disease. The nurses are assisted by dieticians, 
pharmacists, and social workers who come in daily to conduct classes in the visitors' lounge. Each day a different class is taught, using lectures and discussions of diet, medications, psychological aspects of cardiac disease, and risk reduction. Family members are invited to attend these classes. This is not a formal program, and patients are at liberty to choose which classes they wish to attend. The short length of stay ( 2 to 3 days) does not allow for attendance at all sessions.

There continues to be a need to empirically examine the effectiveness of programs for hospitalized cardiac patients. The present study reflects the development, implementation, and evaluation of telephone follow-up after hospital discharge as one method of modifying patients' behaviors in order to reduce risk factors for cardiac disease.

\section{Statement of the Problem}

Patients' desire to change behavior, but failure to achieve this goal after discharge from the hospital, is the problem. The emphasis on teaching information to hospitalized patients, rather than changing attitudes and perceptions, has proven to be ineffective (Briody, 1984). Providing information to patients about their disease while hospitalized does not appear to increase compliance in behavioral modifications after discharge.

Lack of continuity and support for patients after hospital discharge has been identified as a problem (Scalzi, Burke, \& Greenland, 1980). Hospitalized patients who express a sincere desire to stop smoking, lose weight, exercise on a regular basis, lower their cholesterol levels, and utilize stress reduction techniques often fail to accomplish any of these goals after they are discharged (Steele \& Ruzicki, 1987). Without support and frequent reinforcement, they lose incentive and motivation, and fail in their attempts to embark on a risk reduction program upon returning home (Scalzi et al., 1980). These patients require a plan that will 
enable them to carry out their desired goals. Follow-up by a health care professional through telephone contact can provide reinforcement and reassurance to these patients.

Telephone follow-up as an effective intervention for cardiac patients has been substantiated by numerous studies (Bertera \& Bertera, 1981; Garding, Kerr, \& Bay, 1988; Kirscht, Kirscht, \& Rosenstock, 1981; Pozen, Stechmiller, Harris, Smith, Fried, \& Voight, 1977). There are many potential advantages for using the telephone to teach patients: cost-effectiveness in providing reinforcement to stable patients over time, convenience for the consumer, and delivery of information to the patient in the setting in which the behavioral changes are to take place. Bertera and Bertera (1981) found that telephone intervention has a greater impact on behavior modification than clinic counseling. Thus, telephone follow-up has demonstrated potential for effective intervention with patients after discharge from the hospital.

An important aspect of telephone contact is that it enables teaching after the patient is discharged from the hospital. There are several factors which hinder progress in teaching hospitalized patients: (a) limited time allowance for staff nurses, (b) shortened length of hospital stay, and (c) patients' inability to focus or concentrate on the material being taught. In addition, providing information to patients about their disease while they are still hospitalized does not appear to increase compliance (Kirscht et al., 1981).

Acquisition of correct information is only one of the many factors that influence behavior change (Sivarajan, Newton, Almes, Kempf, Mansfield, \& Bruce, 1983). Readiness to learn may not occur until adjustments to life style changes are being made at home after discharge (Garding et al., 1988). Thus, 
telephone follow-up contact can be more practical for the nurse and more meaningful and generalizable for the patient.

Null Hypothesis

At the end of 3 months, there will be no difference in self-reporting of behavioral changes between angina patients who are followed-up by telephone contact after discharge from the hospital by the nurse educator (experimental group) and those who are not (control group). Behavioral changes measured were:

1. Smoking cessation.

2. Knowledge of cholesterol level.

3. Attainment of desirable weight goal.

4. Number of urgent care or emergency room (ER) visits.

5. Usage of nitroglycerine for angina pectoris.

6. Engaging in aerobic exercise at least three times a week.

7. Number of office visits for cardiac-related problems.

8. Participation in a risk reduction class or program.

9. Level of satisfaction with care received.

10. Compliance in taking medications.

\section{Alternative Hypothesis}

Alternatively, it was hypothesized that subjects in the experimental group would exhibit the following changes in behavior at the conclusion of the study:

1. Smoking cessation.

2. Increased knowledge of cholesterol levels.

3. Attainment of desirable weight.

4. Decreased number of visits to urgent care or ER.

5. Decreased usage of nitroglycerine. 
6. Increased aerobic exercise.

7. Fewer office visits for cardiac-related problems.

8. Increased participation in risk reduction classes or programs.

9. Increased satisfaction with care given.

10. Compliance in taking medication.

\section{Purpose and Need}

The purpose of this study was to evaluate the effectiveness of telephone follow-up intervention by a cardiac educator nurse (CEN). This intervention was studied as one method of reducing risk factors in patients admitted to the hospital with a diagnosis of angina pectoris.

Telephone calls have been used in several medical facilities to make personal contact and provide support to individuals undergoing life style changes (King, Taylor, Haskell, \& DeBusk, 1988; Taylor, Houston-Miller, Killen, \& DeBusk, 1990). Evidence suggests phone call interventions are a cost-effective means to assist individuals in adopting and maintaining behavior changes. A cardiac educator nurse to initiate inpatient education to persons hospitalized for angina and to follow-up after hospital discharge with regularly scheduled telephone calls would provide quality care in a cost-effective manner (Bertera \& Bertera, 1981). Patients with a diagnosis of angina are an ideal group to target since they have not yet suffered any significant myocardial damage, are at high risk, and would beneît from primary prevention efforts. The CEN would provide continued support and education to patients and motivate them to make lifestyle changes once they were at home. This could reduce their risk for future cardiac events and enhance their sense of well being.

Although the literature over the past 25 years shows a proliferation of information regarding cardiac teaching programs for patients with diagnosed 
myocardial infarction (MI), documented research on prevention programs before an MI has occurred is only now beginning to emerge (Ornish et al., 1990). The study by Ornish and associates was the first conducted on patients outside the hospital setting. The results showed strong evidence that lifestyle changes alone could bring about regression of severe coronary atherosclerosis within 1 year. The authors of the study recommend that further research be carried out on patients with coronary atherosclerosis to determine the effectiveness of making lifestyle changes in reducing risk for an MI (Ornish et al., 1990).

The present study was intended as a pilot program to address the needs articulated in the literature on health promotion. Using Pender's (1987) health promotion model as a conceptual framework for the program, this study explored the effects of telephone follow-up intervention as a means of reducing risk factors in patients' post hospitalization. The concept of a cardiac educator nurse was introduced as the liaison between patients (with a diagnosis of angina), physicians, and other health care providers at a medical facility.

Definitions

1. Cardiac educator nurse (CEN) is a registered nurse who has had extensive advanced education in coronary disease and treatment, including teaching and communication skills. The nurse also has expertise in cardiac risk factors and methods for changing behavioral life styles.

2. Angina (pectoris) refers to paroxysmal thoracic pain, with a feeling of suffocation and impending death, due, most often, to anoxia of the myocardium, sometimes resulting from spasm of the coronary arteries, precipitated by effort or excitement, and often relieved by nitroglycerine (Blakiston's Pocket Medical Dictionary, 1973; Dorland's Illustrated Medical Dictionary, 26th Edition, 1985). 
Unstable angina refers to angina which is refractory to activity modification or drug therapy as prescribed by a physician.

3. Myocardial infarction (MI) is a heart attack, i.e., the development of an infarct (area of necrosis due to lack of blood supply) in the myocardium, usually the result of myocardial ischemia following occlusion of a coronary artery (Taber's Cyclopedic Medical Dictionary, 1977).

4. Cholesterol level is a lab determination from a serum sample which indicates the amount of cholesterol circulating in the bloodstream.

5. Risk factors are the lifestyle habits affecting one's predisposition to coronary heart disease. These 5 factors are smoking, high blood pressure, obesity, high serum cholesterol level, and stress (Shurtleff, 1974).

6. Transitional Care Unit (TCU) describes the hospital unit where angina patients are commonly admitted. In this study, the cardiac education program is based in this unit.

7. Monitoring patients entails attaching them to a device that relays the electrical activity of their hearts to a screen at the nurses' station where the rhythms are observed and recorded.

\section{Sample and Setting}

The sample included all patients who were admitted to the TCU of a large urban hospital over a period of 6 months with a diagnosis of angina pectoris that was confirmed upon discharge, who agreed to participate, and who met the following criteria:

1. Were 70 years of age or younger.

2. Spoke and understood English.

3. No history of irreversible cardiomyopathy.

4. No history of diabetes. 
5. No history of a documented MI.

The experimental group included eligible angina patients who were admitted to the unit every other week for 3 months. The control group included eligible angina patients who were admitted on the alternate weeks. Even weeks were selected for the experimental group by a random draw. This assignment of patients limited contact between control and experimental patients. It also decreased the possibility of control patients feeling that they were receiving inferior or less treatment.

\section{Data Collection}

A convenience sample of patients (Kuzma, 1984) was used. These subjects were self-selected in that they were already admitted to the hospital. Each patient admitted to the TCU with a diagnosis of angina was contacted by the CEN and offered the option to participate in the study. In order to remember each patient after discharge, the CEN took a Polaroid photograph of each one on admission. A signed consent (Appendix C) was obtained for this procedure. This was helpful in identifying patients during ensuing months.

On the first day of admission to the TCU, individuals in both experimental and control groups were interviewed by the CEN and an intake questionnaire (Appendix A) was completed by the nurse and the patient. After discharge, at the end of 3 months, both experimental and control groups were sent a follow-up questionnaire (Appendix B) with a stamped, addressed envelope, and instructions to fill out and return to the CEN.

Telephone follow-up of the experimental group was done at 5 days, 10 days, 4 weeks, and 3 months post hospital discharge. The control group received only one telephone follow-up 3 months after hospital discharge, after they received the 
follow-up questionnaire. The information gathered through the telephone calls was documented on the Patient Progress Record (Appendix D).

\section{Research Design}

The design of this study was quasi experimental in nature. It compared behavioral changes between experimental and control groups that occurred as a result of experimental interventions.

Descriptive statistics were used to organize and summarize the data. Ten variables were evaluated to measure the effects of the experimental intervention: (a) smoking cessation, (b) knowledge of cholesterol level, (c) desirable weight, (d) Emergency Department visits, (e) NTG usage, (f) aerobic exercise, (g) office visits for cardiac problems, (h) participation in health promotion classes, (i) satisfaction with care, and (j) medication compliance. 


\section{Chapter 2}

\section{CONCEPTUAL FRAMEWORK AND REVIEW \\ OF THE LITERATURE}

The Health Belief Model (Becker, 1974) described by Rosenstock (1988) has been used to explain patient compliance in following prescribed diet, medication, and treatment regimens. Becker and Janz (1984) elaborated on the many interventions needed to influence compliance behaviors. These include raising information and skill levels, altering characteristics of the regimen, assisting to modify health-related attitudes, improving various aspects of the relationship between the provider and patient, enlisting social supports such as the family, and utilizing all members of the health care team. Becker (1974) reported that compliance is a complex issue, with knowledge of the therapeutic regimen being just one potential factor in influencing behaviors.

\section{Health Promotion Model}

In 1987, Pender expanded the Health Belief Model of Becker to emphasize the importance of "cognitive mediating processes in the regulation of behavior" (Pender, 1987, p. 60). Pender's Health Promotion Model is based on a synthesis of research findings from studies of health promotion and wellness behavior. These studies showed that health promoting behaviors are continuing activities that must be an integral part of an individual's life style. "Health-promoting behaviors are an expression of the actualizing tendency and are directed toward maximizing positive arousal such as increased self-awareness, self-satisfaction, enjoyment, and pleasure" (Pender, 1987, p. 59). Figure 1 illustrates the connection between the cognitive-perceptual factors and the modifying factors which lead patients to participate in health-promoting behavior. 
Cognitive/Perceptual Factors

Modifying

Factors

Participation in

Health Promoting

Behaviors

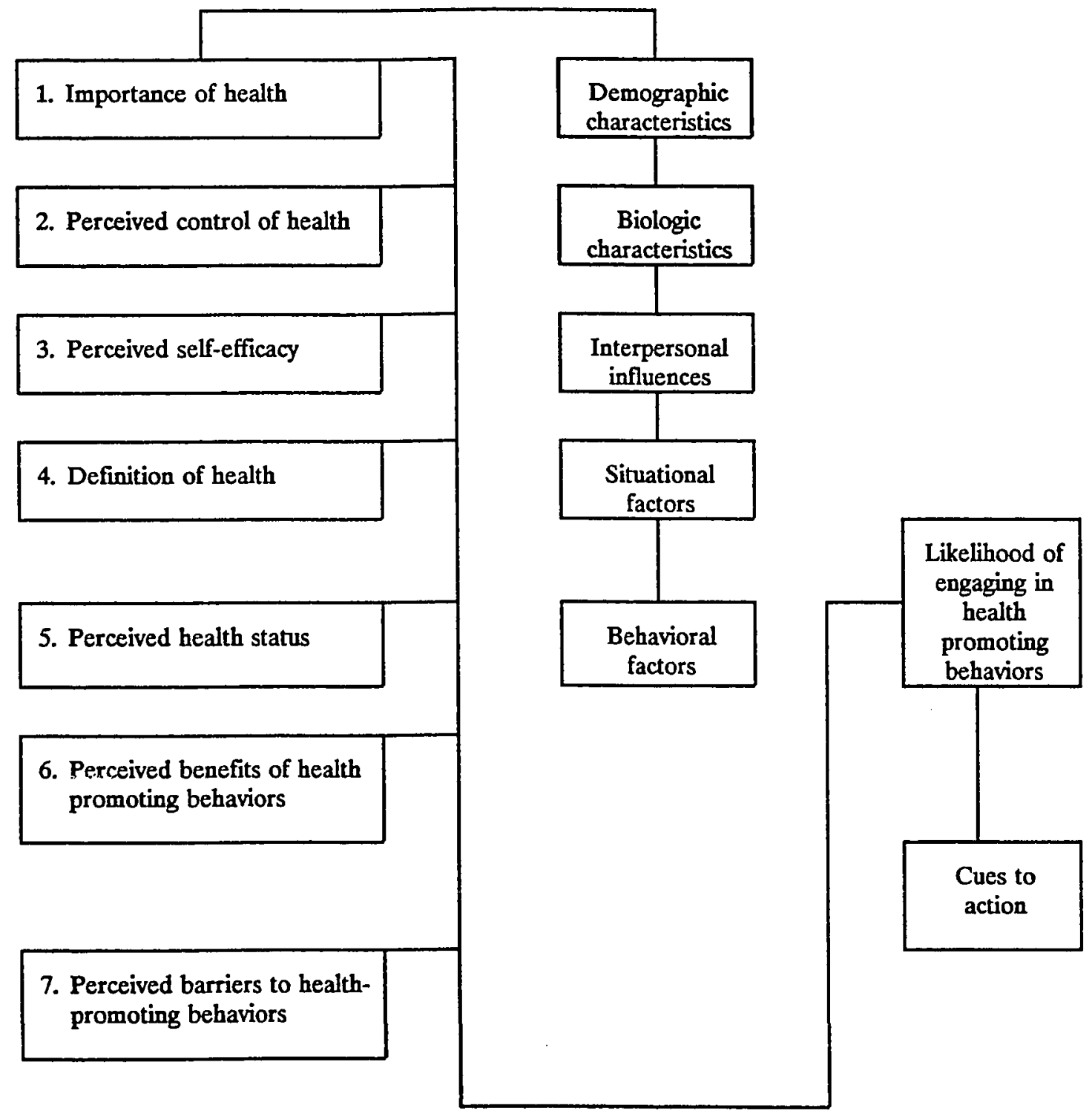

Figure 1. Health Promotion Model.

Note: From Health promotion and nursing practice by N. J. Pender (1987).

Norwalk, CN: Appleton Lange, p. 58. 
Pender stresses the importance of nurse/client follow-up to facilitate continued practice of health behaviors. This follow-up can be a letter, a home visit, or a telephone call. This follow-up phase of health promotion maintains a supportive relationship with continuing clients.

Application of the Health Promotion Model to this study directs the emphasis of nursing intervention to promoting health and increasing the level of wellness. The model for health promotion fulfills three important functions: (a) introduces order among concepts that may explain the occurrence of healthpromoting factors, i.e., risk factors that may lead to cardiac disease; (b) provides for the generation of hypotheses to be tested empirically; and (c) integrates disconnected research findings into a coherent pattern. The collection and analysis of the data will demonstrate a pattern of learning that can be incorporated into nursing practice.

Pender's model views the patient as a proactive participant who acts on the environment to raise his level of health rather than passively reacting to threats or influences posed by the environment. The CEN can use this model to influence patients in promoting their health awareness and optimally increasing their levels of health. This can be achieved by following the outline of the model's cognitiveperceptual factor.

The first factor, the importance of health, is addressed by the CEN on first contact with patients. The intake questionnaire (Appendix A) determines the patients' existing perception of health status. This is a starting point for the CEN to motivate the patients to change their behaviors toward a higher level of health.

Perceived control of health, the second factor, is gained through the initial interview with patients. The CEN encourages patients to take charge of their health by soliciting input from them as to what behavioral changes will enhance 
daily activities of living. During this first interview, the CEN can also assist patients in determining what risk factors are present, which ones are immutable, and which ones can be lessened or removed through behavioral changes.

The third factor, perceived self-efficacy, is important in providing motivation for behavior changes. This is a concept that refers to individuals' convictions that they can successfully execute the required behavior necessary to produce a desired outcome (Bandura, 1986): Pender cites the findings of DiClemente (1981) and Condiotte and Lichtenstein (1981). Both studies found that perceived self-efficacy was an important factor in the maintenance of smoking cessation. They found that perceived inefficacy increased vulnerability to relapse following a period of cessation. Pender also cites other studies that relate increased self-efficacy perceptions to high levels of achievement in weight loss and walking regimens (Pender, 1987, p. 62). The CEN promotes the patient's self-efficacy perception through education, dialogue, and praise for setting up and following prescribed behavioral changes related to high risk factors.

The definition of health to which individuals subscribe is the fourth factor. Pender (1987, p. 64) points out that the prevailing definition of health in the medical community is "absence of illness." If hospitalized patients define their health as being pain free rather than feeling optimally well, they will have less incentive to work through uncomfortable changes to achieve their goals. The CEN must encourage patients to set goals for high-level wellness as opposed to absence of illness.

The fifth factor is health status. This factor appears to play a role in the frequency and intensity of health-promoting behaviors (Pender, 1987, p. 65). Pender cites several studies that found that individuals who perceived their health status to be good reported a higher frequency of health-promoting behaviors than 
did individuals who perceived their health status to be poor (Christiansen, 1981; Dishman et al. 1985; Kaplan \& Cowles, 1978; Luikart, 1972; Pender \& Pender, 1986). It would be challenging to alter patients' perceptions of their health status when they have been admitted to the hospital for an acknowledged illness. However, the CEN can use this awareness of the perceived health status factor in discussing goals for patients when they return home. Enrollment in risk reduction classes and exercise programs should be encouraged with constant positive reinforcement of the patients' progress toward wellness goals.

The sixth factor, perceived benefits of health-promoting behaviors, must be taken into consideration by the CEN when suggesting behavioral changes for patients. Pender points out that perception of benefits from health-promoting behavior appears to facilitate continued practice. In addition, repetition of the behavior appears to strengthen and reinforce beliefs about benefits. Consistency and repetition are important factors in providing activities to patients that will be perceived as benefits to their health.

The final factor, perceived barriers to health-promoting behavior, is crucial. It exerts a direct influence on patients' predisposition to engage in healthpromoting behaviors. Real or imagined barriers to health-promoting behaviors must be identified by the CEN early in the change process. Limitations, both physical and psychological, as well as real and imagined, must be taken into account and discussed with patients when embarking on a new health program. Modifiers of the cognitive-perceptual factors within the model include characteristics such as age, sex, race, ethnicity, education, and income. Interpersonal influences also are modifying factors and include expectations of significant others, family patterns of health care, and interactions with professionals. This last modifying factor is of paramount importance in this study. 
The influence of a health professional on patients' behaviors can be extremely significant during the vulnerable period between hospitalization and return to daily activity.

Telephone follow-up by the CEN is one method to provide for continuous encouragement, reassurance, and reiteration of the regimens to be followed. Interactions with health professionals have a profound effect on the healthpromoting behavior of individuals. Pender (1987, p. 100) describes a physical activity program for adults, effective mainly because of the competent participation and direction by health professionals. It is this human interaction that is the key ingredient.

\section{Literature Review}

Epidemiological and clinical data support the correlation between life style patterns and the incidence of heart disease. Changes in blood pressure, cigarette smoking habits, serum cholesterol levels, diet, and exercise may influence clinical status and the likelihood of further coronary events (Kannel et al.,1986; Kramer et al., 1983; Schlant, Forman, \& Stamlet, 1982). Recent evidence demonstrates the reversibility of atherosclerosis in patients with coronary artery disease treated with aggressive diet and drug therapy to lower their serum cholesterol levels (Blankenhorn et al., 1987; Levy, Brensike, \& Epstein, 1984). Ornish et al. (1990) recently completed a study on patients with severe atherosclerosis who showed regression of the disease after a year of lifestyle changes alone. Structured outpatient teaching programs for post myocardial infarction (MI) patients are extremely common.

Increasing patients' knowledge was thought to result in change of life style and therefore decrease the risk for further cardiovascular disease. Many such programs have demonstrated effectiveness in increasing patients' knowledge 
(Barbarowicz, Nelson, DeBusk, \& Haskell, 1980; Murdaugh, 1982; Scalzi et al., 1980). However, it has been shown that knowledge alone does not change behavior or lead to compliance with medical regimes (Sivarajan et al., 1982; Steele \& Ruzicki, 1987). In addition, anxiety is highest in these patients early in the illness, immediately after transfer from the critical care unit, and prior to discharge from the hospital (Murdaugh, 1982).

In an investigation of knowledge gains in patients with cardiac disease, Scalzi et al. (1980) concluded that retention of information was limited after negligible gains from teaching programs during hospitalization. There was evidence to suggest that a postdischarge teaching program had a positive effect on knowledge and reported compliance with medications, exercise, weight reduction, and symptom management. Scalzi et al. (1980) noted that during the first 6 weeks after discharge patients and families seemed to have more questions and need more guidance than had been anticipated. "This may be a period when patients are more receptive to instruction. However, the current structure of follow-up care tends to perpetuate the disruption in continuity of the instructional process" (Scalzi et al. 1980, p. 853). Pozen et al. (1977) were able to demonstrate that teaching given by a hospital-based rehabilitation nurse was effective in facilitating return to work, improving patient knowledge, and decreasing smoking.

Fletcher (1986) studied the effect of rehabilitation after coronary angioplasty and reported the low knowledge retention rate of patients while in the hospital. Although patients were educated by staff nurses on risk factors and behavior modification while hospitalized, 30 patients post angioplasty showed very low compliance 3 months after discharge. Results of the study showed a need for post hospitalization follow-up when patients are better able to assimilate the . information provided by the educator. Pender $(1987$, p. 65$)$ points out that 
health-promoting behavior relies on the ability of the guide to help clients explore their health situations and define concerns. A nurse has the necessary skills to assist clients in activities, including values clarification, self-assessment, goal setting, information acquisition, decision making, planning behavior change, implementing life-style modification, sustaining health-promoting behaviors over time, and social support building.

The effectiveness of the nurse as an educator for patients with cardiac disease has been well documented (Scalzi et al., 1980). Interventions such as imparting information and including family members in teaching sessions have not consistently enhanced compliance. Linde and Janz (1979) and Scalzi et al. (1980) concluded that, although knowledge retention is limited during the inpatient phase of hospitalization, reinforcement after discharge may help improve knowledge and compliance. This is noted most during the first 6 to 8 weeks after hospitalization when patients and families have many questions.

Stanford University, California (DeBusk et al., 1988) is now conducting a large research project on MI patients who are receiving follow-up education by a nurse clinician to evaluate a multifaceted intervention for risk factor modification commencing soon after MI. In previous studies on MI patients (DeBusk, 1985), the Stanford group noted the importance of telephone surveillance provided by a nurse clinician to review patients' progress and to provide additional information and support after discharge from the hospital.

The hospital staff nurse's perception of what information the patient needs is often quite different from the patient's perception of what he needs (Grady, Buckley, Cisar, Fink, \& Ryan, 1988). Bilodeau and Hackett (1971) identified a number of concerns expressed by a group of patients with MI after discharge from the hospital. Concerns were related to illness, medication, risk factors, and 
personal health status. Although some of these were touched on briefly during the hospital stay, the patients did not feel they had enough time or energy to effectively cover all points of concern. The telephone was used as a method to reduce anxiety and fear, by providing follow-up teaching and support for the patient at home.

The telephone has also been used as a means of personal contaci and social support in a variety of risk factor modification programs. Among hypertensive patients, phone calls by a social worker every 3 weeks for 6 months produced lowered median blood pressures in the treatment group (Bertera \& Bertera, 1981). In another hypertension study, a project nurse called each participant to discuss the regimen and to reinforce any positive steps which the patient had already taken. This resulted in increased adherence to taking medication (Kirscht \& Kirscht, 1981). In another randomized study, adoption and maintenance of exercise were enhanced by regularly scheduled phone contacts by project staff. The subjects who received supportive telephone contacts biweekly from the staff significantly increased their oxygen uptake through exercise (King, Taylor, Haskell, \& DeBusk, 1982). Similarly, daily phone calls to an answering machine was 1 of 4 strategies which produced comparable improvements in weight and smoking behaviors among healthy volunteers (Jeffrey, Danaher, Killen, Farquhar, \& Kinnier, 1976). Weekly 5 minute phone calls for 10 weeks produced similar weight loss to weekly 1 hour face-to-face counseling in groups of university campus volunteers (Lindstrom, Balch, \& Reese, 1976).

Periodic contacts with the nurse over time can facilitate continued practice of health behaviors (Pender, 1987, p. 99). The very nature of most healthprotecting and health-promoting behaviors require their continued performance throughout the life span. Imbuing patients with the perception that they are 
empowered to take control over health-promoting behaviors can lead to achievement of this goal.

Cost-effectiveness of telephone follow-up programs is rarely documented in the literature. Bertera and Bertera (1981) discuss cost savings in terms of telephone follow-up as compared to clinic visits. Pozen et al. (1977) refer to the problem of great social and economic magnitude of patients not returning to work after an MI due to psychosocial maladjustments. 
Chapter 3

METHOD

Introduction

This study used a quasi-experimental design with both an experimental and a control group who completed intake and follow-up questionnaires. Only the experimental group received continued contact by the cardiac education nurse (CEN) with regularly scheduled telephone calls. This formal program consisted of the CEN's advice and intervention in 10 areas: (a) smoking, (b) cholesterol, (c) diet, d) E.R. visits, (e) NTG usage, (f) exercise, (g) office visits, (h) class enrollment, (i) satisfaction with care, and (j) medication compliance.

\section{Subjects}

Fifty-four patients who were hospitalized with a diagnosis of angina pectoris and satisfied the criteria described previously agreed to participate in the study. The sample consisted of 39 men and 15 women. The average age of the subjects was 53.4 years. The majority were Caucasian, married, and were employed. Of the original 54 patients selected and who agreed to participate in the study, only 12 returned questionnaires ( 7 experimental and 5 control). Repeated requests by telephone and 2 repeat mailings of questionnaires did not elicit an increased response. Data are reported for the 12 patients who completed the study.

Approval was obtained from the Protection of Human Subjects Review Committee of San Jose State University for the proposed study and the data collection instrument after it was piloted for clarity and content validity (Appendix E). The Hospital Administrator and Director of Nursing permitted the investigator to use their population for the study (Appendix F). Each patient signed a consent form before participating in the study (Aprendix G). . 


\section{Instruments}

The intake and follow-up questionnaires (Appendices A and B) were designed to correlate with the planned interventions by the CEN. The CEN received specialized training prior to assuming her position. This included instruction in interviewing techniques by experts in the Medical Center Education Department. She met regularly with the chief cardiologist to discuss methods of eliciting accurate information from patients and how to communicate accurately with patients.

The questionnaires were developed with the assistance of Nancy Gordon, Ph.D., educator and researcher for Kaiser Hospital Regional Education Department, and were piloted in the TCU for 3 months to check for validity. The intake questionnaire was primarily designed to collect demographic data for the CEN for reference during telephone follow-up after discharge. It was distributed to the cardiologists; comments were favorable on its use. The CEN found it to be an acceptable tool for determining patients' risk factors and knowledge of health status.

The follow-up questionnaire for the study was patterned on the intake questionnaire. This ensured that the 10 variables to be studied would be included in the follow-up telephone calls, and the patients would be familiar with the general language of the questionnaire. There were 30 questions on the intake and 25 questions on the follow-up questionnaire.

The first 10 questions on the questionnaire were intended to discover the patients' risk factors relating to cardiac disease. They included questions regarding hypertension, cholesterol level, smoking habit, weight, and family history of heart disease. 
Questions 11 through 14 were designed to elicit the kinds of foods and amounts per week that patients were eating. The questions on diet were quite specific about types, amounts, and frequency of foods eaten in order to obtain a picture of the patients' intake of foods high in cholesterol and fats. In addition, answers to these questions presented a dietary pattern for patients who stated they felt they were not at normal weight. An example was, "About how many whole eggs (with yolks) did you usually eat a week?" This information was gathered into one summation about the patients' intake of foods high in cholesterol and fats. The follow-up questionnaire had the identical questions about diet in order to get an accurate comparison.

Exercise was questioned by type of physical activity, time spent, and times per week. The variable was measured by multiplying time spent on "aerobic exercise" with number of times per week. This was then compared to the followup question to determine if the patients' exercise had increased.

Three questions dealt with medication compliance, especially NTG usage and whether patients could identify when to take this medication. The investigator also examined how often they forgot to take their medicines with a scale using "always, sometimes, or never," and assigning a number to each answer in order to compare it with the follow-up questions.

General feelings of well being and satisfaction with care given during and after hospitalization were measured by questions rated on a Likert scale from 1 to 6 , with 1 being "all of the time," and 6 being "none of the time." These numbers were added and the overall scores were compared between intake and follow-up questionnaires. Questions about smoking and enrollment in risk reduction classes were compared at the end of the 6-month study. 
Procedure

1. Each day during the week, the CEN checked the roster on the TCU, Coronary Care Unit (CCU), and medical floor for new angina patients. If a patient was eligible to participate, the CEN explained the study and asked the patient to participate. Upon agreement by the patient, the patient read and signed the consent form (Appendix G).

2. The CEN admitted the patient to the study by assigning a code number to the patient and putting a tickler card in the file to ensure appropriate followup. A photograph was taken to aid the CEN in remembering the patient after discharge. A consent was obtained for photography (Appendix C).

3. The CEN checked that the intake questionnaire was completed on both the experimental and control patients either with information from the medical record or with the help of the patient.

4. Patients were weighed on the first day of hospitalization; weight was recorded in pounds. They were asked if they felt their weight was normal, and this question was asked again in the follow-up questionnaire. Metropolitan Life Insurance Tables (1977) were used to define the upper limit of normal weight.

5. All patients were visited by the CEN during their hospitalization. The patients were encouraged to attend all classes provided in the TCU, and were shown a special bedside video tape on angina. Following the viewing of the video tapes, the CEN met with the patients to discuss the tape and to reinforce cessation of smoking, as well as review medications, diet, exercise, and relaxation regimens. Attendance at educational meetings was documented on the Cardiac Education Form (Appendix H). This form was initially filled out by the staff nurses when they admitted the patient and was updated as the patient received more information. 
6. Staff nurses continued to provide usual care in regard to cardiac education, e.g., explaining medications, reminding patients of the classes being held in the TCU, and providing information about available videos and tapes.

7. The CEN met with the patients (and family, if available) 1 to 2 days prior to discharge to assess discharge and educational needs. Appropriate referrals were made.

8. The experimental patients and families were called on days 5 and 10 , and the 4th week following discharge to see how they were doing, what their needs were, and whether they were following the prescribed regimens or needed reinforcement. Each telephone call was documented (Appendix I). The CEN was instructed to elicit pertinent information regarding patients' feelings and perceptions and to encourage patients to continue their new regimens for behavioral changes.

9. At the end of 3 months following discharge, both experimental and control patients were called by the CEN. At this time, they were advised that a follow-up questionnaire had been sent to their homes and were asked to complete it and return it to the CEN in the enclosed, addressed, stamped envelope. During the telephone call, the CEN completed the telephone documentation form.

10. At the end of 6 months, all questionnaires were collected and data were retrieved and organized by a research assistant. The data were tested and correlated according to the hypotheses. Only those questions relating to risk factors relevant to the study were retrieved. The retrieval was accomplished by a college student who compiled and tabulated the data on both the control and experimental groups. 


\section{Chapter 4}

\section{DATA ANALYSIS AND INTERPRETATION}

\section{Analysis of Data}

The objective of this study was to evaluate the effectiveness of a telephone follow-up intervention by a cardiac educator nurse (CEN) in patients hospitalized with a documented diagnosis of angina. This was determined by measuring whether or not telephone follow-up after discharge was an effective means of encouraging patients to change their behaviors in order to reduce risk factors. The CEN's interventions utilized the concepts set forth in Pender's (1987) health Promotion Model.

\section{Data from Original Cohort}

At the end of 6 months, there were 30 control patients and 24 experimental patients. Data obtained by intake questionnaire showed that of the 30 control patients, $73 \%$ were men $(n=22)$, and $27 \%$ were women $(n=8)$. The experimental group consisted of $71 \%$ men $(\underline{n}=17)$ and $29 \%$ women $(\mathfrak{n}=7)$. The mean age of the experimental group was 56.8 years. The mean age of the control group was 54.5 years. Of the control group, $63 \%(n=19)$ worked at least 40 hours per week, $20 \%(n=6)$ were retired, and $6 \%(n=3)$ were on disability. In the experimental group, $62.5 \%(\mathrm{n}=15)$ worked 40 or more hours a week, $25 \%$ $(n=6)$ were retired, and $4 \%(n=3)$ were on disability. In reporting family history of heart disease, $47 \%(n=14)$ of the control subjects and $42 \%(n=10)$ of the experimental group reported a history of hypertension. Race, education, and socio-economic status were not measured. Comparisons were not made by gender due to the small sample size. Table 1 shows demographics of the original sample obtained from the intake questionnaire. 
Table 1.

Demographic Characteristics of Original Cohort

$(n=12)$

Characteristics

Control

Experimental

$\underline{n}=\mathbf{3 0}$

$\underline{n}=24$

n

$\%$

$\underline{n}$

$\%$

Gender

$\begin{array}{lrrrr}\text { Male } & 22 & 73.0 & 17 & 71.0 \\ \text { Female } & 8 & 27.0 & 7 & 29.0\end{array}$

Age

20-30

0

0

$30-40$

4

13.4

0

40-50

9

26.6

$11 \quad 45.8$

50-60

10

36.6

$6 \quad 25.0$

60-70

7

23.4

$7 \quad 29.2$

Employment

8-20 Hours

$2 \quad 06.6$

04.0

40 Hours or more

19

63.3

$15 \quad 62.5$

Retired

$6 \quad 20.0$

$6 \quad 25.0$

Disability

$\begin{array}{ll}3 & 10.0\end{array}$

$3 \quad 04.0$

Family History

\begin{tabular}{crrrrr} 
of Heart Disease & 9 & 26.6 & 5 & 20.8 & \\
Increase B.P. & 14 & 46.6 & 10 & 41.6 & - \\
\hline
\end{tabular}




\section{Data from Subjects Returning Ouestionnaire}

Due to the small number of participants $(22 \%)$ who returned the questionnaire, the analyzed sample $(n=12)$ was 7 experimental and 5 control patients. This was not an acceptable number to perform tests of statistical significance. The small sample size did not present enough data to determine reliability of the null hypothesis through inferential statistics. The alternative hypothesis was summarized through analysis of returned questionnaires and anecdotal material obtained by the CEN through telephone contact. Therefore, the analysis was totally descriptive in nature.

Of the 30 patients in the initial control group, $5(17 \%)$ completed the follow-up questionnaires. Of the initial 24 experimental patients, 7 (29\%) returned the follow-up questionnaires. Only those patients who returned the follow-up questionnaires were included in the study. Table 2 describes the demographic makeup of these 12 patients. Nine (75\%) of the returned questionnaires were from men and three $(25 \%)$ from women.

The behavioral changes that were reported by experimental and control groups in the returned questionnaires are shown by frequency and percentage in Table 3.

Substantial changes in weight were demonstrated in the experimental group, with $6(86 \%)$ of the experimental subjects achieving desirable weight after intervention, compared to no change in the number of control subjects at their desirable weight. Both the amount and time of exercise were increased by 6 (86\%) subjects in the experimental group after invention, while only 3 of the control subjects were exercising and 2 of these had decreased their amount of exercise. More of the experimental group subjects were satisfied with their treatment ( $71 \%$ ) compared to control subjects (60\%), although the majority of both groups were satisfied. The Likert scale showed a mean of 4.5 for the 
Table 2.

Demographic Characteristics of Cohort Returning Questionnaires

$(n=12)$

\begin{tabular}{ccccc}
\hline Characteristics & \multicolumn{2}{c}{ Control } & \multicolumn{2}{c}{ Experimental } \\
& $\underline{n}$ & $\%$ & $\underline{n}$ & $\%$ \\
\hline Gender & & & & \\
Male & 5 & 100 & 4 & 57 \\
Female & 0 & & 3 & 43 \\
Age & & & & \\
$30-35$ & 1 & 20 & 0 & 43 \\
$40-55$ & 2 & 40 & 3 & 57 \\
$50-65$ & 2 & 40 & 4 & \\
Employed & & & & 29 \\
Yes & 3 & 60 & 5 & 2 \\
No & 2 & 40 & 2 & \\
\hline
\end{tabular}


Table 3.

Comparison of Changes on 10 Indicators

Between Experimental and Control Groups

\begin{tabular}{llllll} 
Variables & \multicolumn{2}{c}{ Control } & \multicolumn{2}{c}{ Experimental } \\
& & $\underline{\mathrm{n}}$ & $\%$ & $\underline{\mathrm{n}}$ & $\%$ \\
\hline 1. & Quit Smoking & 0 & & 0 & \\
2. Knowledge of Cholesterol & 4 & 80 & 1 & 14 \\
3. Desirable Weight & 3 & 60 & 6 & 86 \\
4. Emergency Room Visits & 0 & & 3 & 43 \\
5. Exercise & 3 & 60 & 6 & 86 \\
6. NTG Usage & 0 & & 0 & \\
7. Doctor Visits & 1 & 20 & 5 & 71 \\
8. Class Participation & 2 & 40 & 3 & 43 \\
9. Satisfaction & 3 & 60 & 5 & 71 \\
10. Medication Compliance & 1 & 20 & 1 & 14 \\
\hline
\end{tabular}


experimental group versus a mean scale of 3 for the control group. Both in the experimental (43\%) and control (40\%) groups, several subjects were participating in out-patient classes after discharge.

The control group reported better knowledge of cholesterol level than did the experimental group both in the hospital and 3 months after discharge. In fact, 2 of the experimental subjects knew their cholesterol levels at the time of admission to the hospital, and only one did so after discharge.

The experimental group reported more visits to the emergency room. There also were more doctor visits after hospitalization by the experimental group than by the control group.

Based on the sample of returned questionnaires, the experimental group improved in the following ways:

1. Engaged in aerobic exercise at least three times a week.

2. Achieved desirable weight.

3. More experimental subjects than control subjects were satisfied with their treatment.

The experimental group did not improve in the following ways:

1. Smoking cessation, except that the single smoker cut usage in half; however, the number of control group smokers increased by 1 .

2. Knowledge of cholesterol levels.

3. Usage of NTG.

4. Number of office visits for cardiac-related problems and urgent care or emergency room visits after the intervention (numbers increased).

At the end of the study, there were 30 control patients and 24 experimental patients. Only the experimental patients received telephone follow-up by the CEN 5 days, 10 days, and 4 weeks after hospitalization. Anecdotal data from the 
telephone interviews of the 17 experimental patients who did not return the follow-up questionnaire was supportive of the telephone follow-up intervention of the CEN. This was reflected in the documentation of the telephone calls by the CEN and is illustrated by the following comments from patients: "I changed to vegetable oil, no frying, and eating mainly fish and chicken." "I went to the Health Education Center for information on low cholesterol and low fat diets." "I only eat oat bran and high fiber cereal." "I am eating red meat only three times a week now."

In addition, the telephone interviews revealed $3(17.6 \%)$ of the nonrespondent experimental group stopped smoking during hospital stay and had not resumed smoking after 3 months. One patient enrolled in a chemical dependency program. Weight loss was reported by $6(35 \%)$; exercise was increased by 5 (29\%); and 15 (88\%) were enrolled in the outpatient risk reduction class. The CEN intervened with the patient's physician for medication adjustment for 5 patients (29\%).

Several nonrespondent experimental patients commented on the "good care" they felt they had received as well as their appreciation for the follow-up encouragement and advice they received by telephone. The descriptive data retrieved through the telephone follow-up documentation supports the evidence that positive outcomes are achieved through telephone intervention and lead to risk reduction behavior for cardiac patients, as well as increased patient and staff satisfaction. 


\section{Chapter 5}

\section{CONCLUSIONS AND RECOMMENDATIONS}

\section{Conclusions}

Although this study originally sampled 54 subjects, follow-up questionnaires were returned by only 12 subjects, 5 in the control group and 7 from the experimental group. In the final sample, some differences were observed between the experimental and control groups in exercise and weight reduction. Additionally, the experimental group reported, through telephone interviews, definite patterns of increased perception of wellness as defined by Pender (1987, p. 65). Their anecdotal responses reflected a perception of trying to obtain optimal wellness as opposed to perceiving themselves being treated for illness. Furthermore, it could be conjectured that they may feel empowered by their perception of themselves as participants in a health-promoting program which would enhance their lives. This is seen as a positive outcome.

Weight loss by the experimental group changed positively relative to the control group. It appeared that these subjects' weight loss was closely tied to interest in attending follow-up classes on diet and nutrition and increased exercise programs. The outpatient nutrition classes assisted subjects in using discretion in choosing foods low in cholesterol and fat. A trip to the supermarket enabled subjects to see first hand what products are healthy and which ones have misleading labels. Videos describing healthy versus unhealthy diets were valuable to both experimental and control groups in teaching diet. Interestingly, patients involved in cholesterol and fat-reducing programs were able to reduce their weight without feeling that they were having to give up calories. The telephone intervention may have reinforced that perception. 
Increase in experimental subjects' exercise was an important finding. Although there was no formal exercise follow-up program offered by the medical facility, the CEN encouraged patients to participate in an aerobic exercise regimen. The experimental group engaged in exercise at least 3 times a week, reporting, via telephone follow-up, an increased sense of empowerment over their bodies and general feelings of well being.

Intervention by telephone follow-up for smoking cessation showed only a limited effect in this study. However, the efficacy of such intervention has been well documented by the Stanford Multifit study (Debusk \& Haskell, 1986). Changes in smoking were not possible to detect in the small sample. Also, most patients stated that they had stopped smoking upon admission to the hospital. This frequently occurs when patients are frightened by the specter of possible cardiac surgery or the impending threat of a heart attack (Sivarajan et al., 1983). The enrollment of subjects into risk factor-reducing classes after discharge may have had an effect on smoking cessation that was not measured.

While there was no substantial change in knowledge of cholesterol levels, the control group reported they knew their cholesterol levels after discharge, while the experimental group as a whole reported they did not. Actually, two experimental respondents knew their cholesterol levels prior to intervention, but only one did after intervention. This may be explained, in part, by the fact that the experimental patients were instructed by the CEN to ask for a repeat cholesterol test upon their first return visit to their doctor. At the time the questionnaire was returned, the patients had not yet had their return visit and could not accurately report a new level. Another factor that may have affected the results was the physicians' cooperation in ordering serum cholesterol tests 
after hospitalization. These were not routinely ordered on every patient after discharge.

The amount of NTG used did not change in the control and experimental groups. However, the experimental group did report better understanding of when and how to take NTG in conjunction with anginal pain.

There was no difference in medication compliance between the experimental and control groups. This relates directly with findings that patients do not hear or retain information related to health problems unless there is constant repetition and explanation (Garding, Kerr, \& Bay, 1988). Perhaps 3 telephone calls were not adequate.

Although visits to the emergency room increased in the experimental group, it was believed that this was due to increased knowledge and heightened sensitivity to symptoms of angina that had previously been ignored. Each telephone call to the experimental group included reemphasis on warning signs and instructions for intervention for anginal pain.

It was concluded, after telephone follow-up, that experimental subjects' increased awareness of their illness led to heightened sensitivity about their care after hospitalization. The increased number of emergency room visits was not interpreted as necessarily a negative outcome. Although these subjects were more sensitive, and perhaps more anxious, this provided them with the impetus to improve their health and life style. This ties in with Pender's model of perceived benefits of health-promoting behaviors and perceived barriers to health-promoting behaviors (Pender, 1987, p. 64). Increased anxiety is thought to be a side effect of giving information which heightens the patients' sensitivity to risk factors. Having a small amount of anxiety may induce patients to take steps to reduce risk behaviors. Pozen's study (1977) employing a nurse rehabilitator for MI patients 
had similar findings. "Perhaps counseling and intensive efforts at reassurance in an effort to reduce anxiety actually created some anxiety by detailed discussions of heart disease" (p. 835).

Office visits were not well documented due to lack of resources for retrieval of this information. A recommendation for further study would be to review the number of visits and to ascertain how many of these visits were cardiac related.

Cost-effectiveness of telephone follow-up was not adequately measured due to the small sample size, limitations of tracking and documentation of office visits, and low reporting of phone calls to doctor's offices. While cost-effectiveness is implicit in any change that affects positive patient outcomes, it was not explicit in this study and, therefore, cannot be regarded as a finding of the study.

Two major outcomes emerged from this study. First, telephone follow-up by the nurse educator had positive effects on patients' adaptations to changing lifestyle behaviors: increased feelings of well-being and empowerment, engaging in aerobic exercise, achieving desirable weight, and perceiving care as satisfactory. A second outcome was that the CEN was hired by the participating hospital for a permanent position to continue the cardiac education program. Hospital administrators received sufficient positive feedback from physicians, patients, and nursing staff about the program to give it permanent funding.

\section{Limitations}

The randomization of groups was subject to manipulation according to diagnosis. Due to the limited sample size, it is not possible to generalize beyond this sample or draw statistical conclusions to support or reject the hypotheses.

Other limitations within the program were economic constraints which limited the amount of time the CEN could spend on this study. Also, the variability in the clinical course of patients was a factor. There was no control 
over the variables of medical management, diagnostic tests ordered, the degree of coronary artery disease, patients' educational level, and the amount or kind of social support received.

Methodological limitations included use of self-report measures. Utilization of self-reports for data collection always presents the question of accuracy. It was beyond the scope of this study to determine if patients were responding factually or whether they may have been answering according to social desirability (Grady et al. 1988). Additionally, the small return of follow-up questionnaires placed severe limitations on the study.

\section{Recommendations}

Recommendations for future studies include increasing the sample size, providing a longer period of time for data collection, decreasing the number of variables studied, and increasing resources. Resources should include staff to retrieve and record data and assist in obtaining completed questionnaires from the subjects in the study.

The small sample size limited comparisons and generalizability. Although the small sample may have been representative of the group being studied, statistical analysis was limited.

Time is a most valuable resource. In order to accurately measure behavioral changes, subjects need time to absorb, evaluate, and act upon the changes necessary to improve their life styles. The time frame of the present study allowed only a beginning for most of these changes. Hopefully, those subjects who are in the process will continue to reduce their risk factors over time.

Working with individuals who are anxious, in pain, and hospitalized for a very short period of time (usually less than 3 days) requires time and energy on the part of the CEN. Concentrating on those areas that are of greatest concern, 
for example, cholesterol reduction and smoking cessation, might be more effective and produce better data than attempting to look at multiple variables such as was done in this study. While all the risk reduction variables are interactive, focusing on 2 or 3 areas would be more productive.

Future studies should evaluate other methods for obtaining information from this group of subjects. Written questionnaires fared poorly in this study. When asked by telephone why the questionnaire was not returned, subjects stated that they had returned them and they must bave become lost, they were still going to return them, or they had misplaced them. Ironically, the subjects reported they thought the questionnaire was the best method for obtaining information. When asked to complete the questionnaire over the telephone, almost all of the subjects refused, saying they would rather mail the questionnaire because they needed more time to think about the questions. However, the questionnaires were not received. Subjects' refusal to comply, even after agreeing to participate and after being urged to do so by telephone follow-up, shows that this investigative modality has inherent limitations in this study.

Although questionnaires have been successfully used in many studies (Grady et al., 1988; Raleigh \& Odtohan, 1987; Stampfer, Willett, Colditz, Speizer, \& Hennekens, 1988; Steele \& Ruzicki, 1987), the group response rate in the present study was unacceptable. Raleigh and Odtohan (1987) administered their post questionnaire through a home visit by a research assistant. This insured that the data were collected and returned at a prescribed time. The posttest administered by Steele and Ruzicki (1987) was completed by patients while still in the hospital. Grady et al. (1988) administered their post discharge questionnaire during their subjects' return visits to the outpatient clinic. Stampfer et al., (1988) mailed questionnaires to registered nurses at 2-year intervals (Nurses' Health Study 
cohort) to evaluate the effects of oral contraceptive usage on risk for cardiovascular disease. The compliance in returning questionnaires in Stampfer's study may possibly be ascribed to the cohort representation (registered nurses) who may be more willing than others to fill out questionnaires. A recommendation is that future studies may be modified by conducting face-to-face exit interviews at the end of the study. At that time, the data could be obtained and the concepts to be inculcated could be reinforced.

This study cannot be generalized to all patients hospitalized for angina pectoris. It has validity, however, in demonstrating the need for further research into follow-up interventions for changing risk behaviors in patients after discharge. It is recommended that this study be replicated with larger sample sizes. While hospitalized patients exhibit readiness to learn (Steele \& Ruzicki, 1987), it might also be effective to explore the possibility of providing ongoing contact with patients who have not been hospitalized but who may be diagnosed with angina or arteriosclerotic heart disease. Engaging these patients in activities that raise cognitive perceptions of health behaviors (Pender, 1987, p. 61) might possibly lead to positive results in long-term health promotion and prevention of illness.

Motivating patients to participate in a health promotion program is vitally important and must be an ongoing goal for the nurse. Unless patients feel empowered to move forward toward a goal of health, rather than run away from the specter of disease, they will not be proactive in making lifestyle changes that can enhance the quality of their lives. Pender (1987) states: 
Individuals of all ages are beginning to assume increased responsibility for their own health and to expect greater mastery of personal and environmental factors that impinge on health. It is possible that those people with positive perceptions of their health promotion skills may be more likely to initiate actions that enhance health. (p. 63) 
REFERENCES 
References

Barbarowicz, P., Nelson, M., DeBusk, R. F., \& Haskell, W. (1982). A comparison of in-hospital education approaches for coronary bypass patients. Heart and Lyng, 9, 127-133.

Bandura, A. (1977). Self-efficacy: Toward a unifying theory of behavioral change. Psychological Review, 84, 119-215.

Becker, M. (1974). The health belief model and personal health behavior. Health Education Monogram, 2, 324-508.

Bertera, E. M., \& Bertera, R. L. (1981). The cost effectiveness of telephone vs. clinic counseling for hypertensive patients: A pilot study. American Journal of Public Health, 71, 626-669.

Bilodeau, C. B., \& Hackett, T. P. (1971). Issues raised in a group setting by parents' recovery from a myocardial infarction. American Journal of Psychiatry, 128, 105-109.

Blankenhorn, D. H., Nessim, S. A., Johnson, R. L., Sanmarco, M. E., Azen, S. P., \& Cashin-Hemphill, L. (1987). Beneficial effects of combined colestipol-niacin therapy on coronary atherosclerosis and coronary venous bypass grafts. Journal of American Medical Association, 257, 3233-3240.

Briody, M. E. (1984). The role of the nurse in modification of cardiac risk factors. Nursing Clinics of North America, 19, 387-396.

Christiansen, K. E. (1981). The determinants of health-promoting behavior. Unpublished doctoral dissertation. Rush University, Chicago.

Condiotte, M. M., \& Lichtenstein, E. (1981). Self-efficacy and relapse in smoking cessation programs. Journal of Consulting and Clinical Psychology, 49, 648-658.

DeBusk, R. F., \& Haskell, W. L. (1985). Stanford University Multifit Study on patients with myocardial infarction. American Journal of Cardiology, 55, 1-23.

DiClemente, C. C. (1981). Self-efficacy and smoking cessation mainterance: A preliminary report. Cognitive Therapy and Research, 5, 175-187. 
Dishman, R. K., Sallis, J. F., \& Orenstein, D. R. (1985). The determinants of physical activity and exercise. Public Health Reports, 100, 158-171.

Fletcher, G. F. (1986). Rehabilitation after coronary angioplasty--is it effective? Archives of Physician Medical Rehabilitation, 67, 517-519.

Garding, B. S., Kerr, J. C., \& Bay, K. (1988). Effectiveness of a program of information and support for myocardial infarction patients recovering at home. Heart and Lung, 17, 355-362.

Grady, K. L., Buckley, D. J., Cisar, N. S., Fink, N. M., \& Ryan, S. D. (1988). Patient perceptions of cardiovascular surgical patient education. Heart and Lung, 17, 349-354.

Janz, N., \& Becker, M. (1984). The health belief model: A decade later. Health Education Quarterly, 11, 1-47.

Jeffrey, R. W., Danaher, B. G., Killen, J., Farquhar, W., \& Kinnier, R. (1982). Self administered programs for health behavior change: Smoking cessation and weight reduction by mail. Addictive Behavior, 7, 57-63.

Kannel, W. B., Neaton, J. D., Wentworth, D., Thomas, H. E., Stamler, J., Hulley, S. B., \& Kjelsberg, M. O. (1986). Overall and coronary heart disease mortality rates in relation to major risk factors in 325,348 men screened for the MR FIT. American Heart Journal, 112, 825-836.

Kaplan, G. D., \& Cowles, M. A. (1978). Health locus of control and health value in their prediction of smoking reduction. Health Education Monographs, 6 , 129-137.

King, A. C., Taylor, C. B., Haskell, W. L., \& DeBusk, R. F. (1988). Strategies for increasing early adherence to and long-term maintenance of home based exercise training in health, middle-aged men and women. American Journal of Cardiology, 61, 628-632.

Kirscht, J. P., Kirscht, J. L., \& Rosenstock, I. M. (1981). A test of interventions to increase adherence to hypertensive medical regimes. Health Education Quarterly, 8, 261-272. 
Kok, F., Matroos, A. W., \& vanden Ban, A. W. (1982). Characteristics of individuals with multiple behavioral risk factors for coronary heart disease:

The Netherlands. American Journal of Public Health, 72, 986-991.

Kramer, J. R., Kitazume, H. Proudfit, W. L., Matsuda, Y., Williams, G. W., \& Scones, F. M. (1983). Progression and regression of coronary atherosclerosis; relation to risk factors. American Heart Journal, 105, 134-144.

Kuzma, J. (1984). Basic Statistics for the Health Sciences. Palo Alto, CA: Mayfield Publication Co., Palo Alto, CA.

Levy, R. I., Brensike, J. F., \& Epstein S. E. (1984). The influence of changes in lipid values by cholestyramine and diet on progression of coronary artery disease; results of the NHLBI Type II coronary intervention study. Circulation, 69, 325-337.

Lindstrom, L. L., Balch, P., \& Reese, S. (1976). In person versus telephone treatment for obesity. Journal of Behavioral Therapeutic Experiments in Psychiatry, 7, 367-369.

Luikart, C., \& Palmore, E. (1972). Health and social factors related to life satisfaction. Journal of Health and Social Behavior, $13,68-80$.

Metropolitan Life Insurance Co. (1977). Trends in average weights and heights among insured men and women. Statistical Bulletin, 85, 2.

Murdaugh, C. (1982, June/July). Using Research in Practice. Focus, pp. 24-28.

Ornish, D., Brown, S., Scherwitz, L., Billings, J., Armstrong, W., Ports, T., McLanahan, S., Kirkeeide, R., Brand, R., \& Gould, K. (1990). Can lifestyle changes reverse coronary heart disease? The lifestyle heart trial. The Lancet, 336, 129-133.

Pender, N. J. (1987). Health promotion in nursing practice (2nd ed.). Norwalk, CN: Appleton-Lange.

Pender, N. J., \& Pender, A. R. (1986). Attitudes, subjective norms and intentions to engage in health behaviors. Nursing Research, 35, 15-18. 
Pozen, M. W., Stechmiller, J. A., Harris, W., Smith, S., Fried, D. D., \& Voight, G. C. (1977). A nurse rehabilitator's impact on patients with myocardial infarction. Medical Care, 15, 830-837.

Rosenstock, I., Strecher, V., \& Becker, M. (1988). Social learning theory and the health belief model. Health Education Ouarterly, 15, 175-183.

Scalzi, C., Burke, L. E., \& Greenland, S. (1980). Evaluation of an inpatient educational program for coronary patients and families. Heart and Lung, 9, 846-853.

Schlant, R. C., Forman, S., \& Stamler, J. (1982). The natural history of coronary artery disease: Prognostic factors after recovery from myocardial infarction in 2,789 men. Circulation, 66, 401-414.

Shurtleff, D. (1974). Some characteristics related to the incidence of cardiovascular disease and death: Framingham study, an 18 year follow-up. In W. G. Kannel, \& T. Gordon (Eds.), The Framingham Study (Publ. No. [NIH] 74-599). Washington, D.C.: Department of Health, Education, and Welfare. Sivarajan, E., Newton, K. M., Almes, M. J., Kempf, T. M., Mansfield, L. W., \& Bruce, R.A. (1982). Limited effects of out-patient teaching and counselling after myocardial infarction: A controlled study. Heart and Lung, 12, 65-73.

Stampfer, M. J., Willett, W. C., Colditz, M. B., Speizer, F. E., \& Hennekens, C. H. (1988). A prospective study of past use of oral contraceptive agents and risk of cardiovascular diseases. The New England Journal of Medicine, 319, 13131317.

Steele, J. M., \& Ruzicki, D. (1987). An evaluation of the effectiveness of cardiac teaching during hospitalization. Heart and Lung, 16, 306-311.

Taylor, C. B., Houston-Miller, N., Killen, J., \& DeBusk, R. (1990). Smoking cessation after acute myocardial infarction: Effects of a nurse-managed intervention. Annals of Internal Medicine, 116, 118-123. 
APPENDIX A

Intake Questionnaire 


\section{ㅇvlily) \\ KaIser Permanente-Haywaro CARDIAC EDUCATION PROGRAM \\ INTAKE QUESTIONNAIRE}

Please print the following information:

Name: $\begin{aligned} & \text { MR. } \\ & \text { MS. }\end{aligned}$

Majling

Address:

FIRST M.T. LAST

Phone number: Day: $(1$

Evening: 11

Personal physician's name:

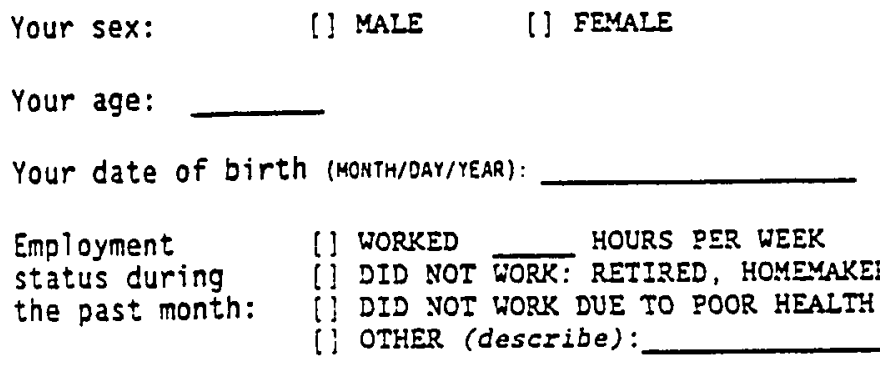

NOW, PLEASE ANSWER THE QUESTIONS ON THE NEXT PAGE 
By answering the following questions, you will help us assess the most appropriate kinds of information and advice that we can give to help you in your recovery.

1. Have you had a parent, brother or sister who had a heart attack, heart bypass surgery, or died suddenly of heart disease before ace 55 ? .................................. [] no [] YES

2. Do you have high blood pressure? ................... [] no [] YES

3. Do you have diabetes (high blood sugar)? .............. [] No [] YES

4. Do you have a high cholesterol level?

[1 NO [] YES

5. When did you last have your cholesterol level checked?

6. Do you know what your blood cholesterol level is in numbers?

If yes, what is it?

7. How would you describe your weight?

VERY

[ ] UNDERWEIGHT

ABOUT

[1] RIGHT

[1] OVERWEIGHT

$V E R$

(] UNDERWEIGHT [] UNDER

8. What is your current weight? Tbs.

9. What do you think you shouid weigh (ideal weight)? Ios.

Please answer the following questions with regards to your lifestyle during the month before viur current hospitalization.

10. Did you smoke eigarettes, cigars or a pipe?

II NO $\rightarrow$ I] I have nover smoked II I quit TMOMTHS OR YERSS ago

1] YES $\rightarrow$ a. How much did you smoke per day:
- cigaretees:
* cigars:
* pipefuls:

b. Have you ever made a serious attempt to quit smoking?

(1) No

if yES $\rightarrow$ When was the last time you tried to quit?

c. Do you want to quit smoking?

(I) No

(1) YES $\rightarrow$ I want to quit within the next 
During the month before your hospitalization:

11. How many times a week did you ysually eat (or drink) the following?

(Each meal or snack = 1 time)

\# Times a week

Red meat, such as beef, pork, or hamburger $\ldots \ldots \ldots \ldots \ldots \ldots \ldots \ldots$

Baked or broiled chicken or turkey

Fish

Cheese (other than cottage cheese)

Cold cuts, hot dogs, bacon or sausage

Fried foods such as fried chicken, potato chips, french fries

Alcoholic beverages (beer, wine, or hard liquor)

Whole milk or ice cream (not nonfat or lowfat)

Fresh fruits and vegetables

Whole grain or oat bran cereal, muffins, pasta, or bread

Pastry, cake, pie, donuts, or cookies

12. About how many whole eggs (with yolks) did you usually eat a week? ...

13. If you drank aicoholic beverages, how many drinks did you usually

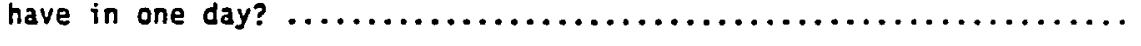

14. How often did you do the following: ALMOST ALUAYS $\frac{\text { OETEN }}{2} \frac{\text { SOMETIMES }}{3}$. NEI:Z

Put salt on or in your food?

Put butter on your food, or eat food cooked in butter? ................. i]

Put margarine on your food, or eat food cooked in margarine or oil? ........... []

Put mayonnaise, suur cream, or salad oil/dressing on your food? ............ []

Eat the skin on chicken or turkey? ........... [1

Eat the fat on meat? .................. []

$\begin{array}{lll}{[1} & {[1} & 1 ! \\ 11 & {[1} & 11 \\ 11 & 1] & 1 ! \\ 11 & 11 & 1 ! \\ 11 & 11 & 11\end{array}$

\section{During the month before your hospitalization:}

15. At least once a week, did you engage in physical activities or exercise strenuous enough to make you work up a sweat or breathe hard? (e.g., jogging, calisthenics, swimming, bicycling, brisk walking, elimbing stairs)

[] NO (SXip TO quEstiox 16) Pl] YES (AMSEER QUESTIOH 15A)

15A: List the types of exercise you regularly got, how long you usually spent doing each physical activity, and how many times a week you usually did it.

ITPE of PATSICu Activity

1.

2.

3.
IIKE_SPEIII

MINUTES

MINUTES

MIMUTES
IIKES PER YIEK

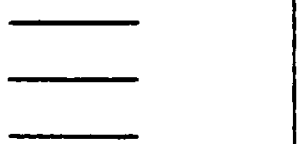


16. During the month before your hospitalization, were you taking blood pressure or heart medicine?

(] NO (SKIP TO QUESTION 21) C] YES (ANSWER QUESTIONS 17-20)

17. If you took nitroglycerine pills: (SKIP TO QUESTION IO IF NOT APPLICABLE)

a. How often did you take them? USUAL OF PILLS PER DAY: _ OR USUAL I OF PILLS FEF WEE: OTHER (OESCRIBE):

b. Did you take them when you had chest pains? I] ALWAYS [] SOMEIIMES [! ::E:E?

c. Did you take them before you exercised?

[1 ALWAYS [I SOMETIMES I: !:EVER

e. When else did you usually take them? (DESCribe)

18. How often did you have trouble remembering to take your medicines at the right times?

(1) AIWAYS [1 SOMETIMES $\vdots:$ ::E::?

19. If you forgot to take your medicine at the right time, what did you usually do?

20. If you had any questions about your medicines or how they should be taken, did you talk with someone (e.g., your doctor or a nurse) to get the information you needed?
[1 No
[] YES, MY DOCTOR
(1) YES, A NURSE
[] DIDN'T HAVE ANY QUESTIC:S

21. This set of questions asks about how you felt and how things were with you during the month before your hospitalization. For each question, please circle the one answer that comes closest to the way you had been feeling.

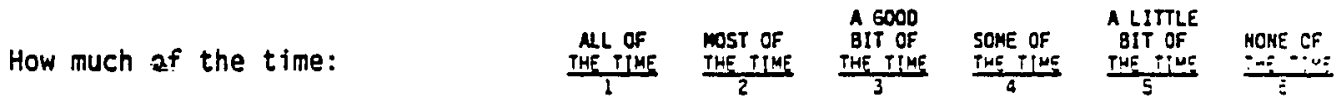

a. Did you feel a lot of stress in your work or personal life? . $1 \quad 2 \quad 2 \quad 3 \quad 4 \quad 5$

b. Were you a very nervous person?

c. Did you feel calm and peaceful?

d. Did you fee? down-hearted and blue? .................... 2 . 3

e. Were you a happy person? ...... I

f. Cid you feel so down in the dumps that nothing could cheer you up? 1

g. Did you act impatient or frritable toward those around you? ...... I

h. Were you worried about your health? .................. I

$i$. Were you afraid to do certain things because of your health? . I

1

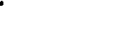

23

23

\section{4}

4

5

5

$\dot{2}$

2

\section{4}

12

12

2

2

2

2

2

3

3

$\begin{array}{lll}4 & 5 & 6 \\ 4 & 5 & 6 \\ 4 & 5 & 6\end{array}$


Please answer the remaining questions with regards to your current situation.

22. How worried are you about your health right now?
NOT AT ALI.
SOMEWHAT
(1) WORRIED
(] WORRIED
FAIRLY
VERY
(1) WORRIED

What are some of the things you are most worried about?

23. How confident are you that you can make changes in your lifestyle to reduce your risk of having a heart attack?
NOT AT ALI
[] CONFIDENT
SOMEWHAT
FAIRIY
(1) CONFIDENT
VERY
(1) CONFIDE:I

24. What kinds of changes would you like to make?

25. Do you think you will attend the "You Gotta Have Heart" outpatient cardias education program given at the Kaiser Permanente-Hayward medical center?

[1 NO $\rightarrow$ Why not?

11 YES $\rightarrow$ Will a spouse or elose friend/relative attend with you? [1 No ij y:5

26. Do you want information about other health improvement classes sponsored by the Kaiser-Hayward facility: (CMECX ALL THAT APPLY)
(1) EXERCISE
(1) LOW CHOLESTEROI DIET
[] STRESS MANAGEMENT
[1 STOP SMOKING
[1] WEIGHT CONTROL
[] OTHER:

27. Do you have any questions about your medicines and iuw they should be taken?

[] No

[] YES (DESCR 1BE):

28. Do you have any questinne about what you should expect during the first few weeks after you leave the hospital?

(1) No

[] YES (OESCRIBE):

29. What other information or help would you like from Kaiser Permanente?

30. Overal1, how do you feel about the care you have received at Kaiser Permanente? [] VERY SATISFIED [] SATISFIED |] DISSATISFIED || VERY DISSATISFIED

Additional comments or suggestions: 
APPENDIX B

Follow Up Questionnaire 
Name:

Date sent:

M.R. Number:

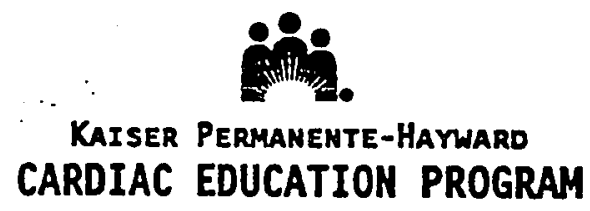

Follow-Up QuestionnaIRE

Please answer the following questions to help us learn what your life has been like during the past few months. If you have trouble filling out the form or have any questions, call Carol Graham, Cardiac Education Nurse, at (415) 784-4584.

Please return the questionnaire in the pre-addressed envelope to: Supervisor, Transitional Care Unit, Kaiser Permanente Medical Center, 27400 Hesperian Blyd., Hayward, CA 94545. Thank you.

Today's date:

1. When did you last have your cholesterol level checked?

WOMTH NOT RER

2. Do you know what your blood cholesterol level was at that time,

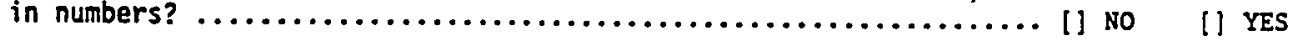

If yes, what was it? (E.G., 260)

3. What is your current weight? Ibs.

Please answer the following questions with regards to your lifestyle during the past month.

4. Have you been trying to lose weight? $\ldots \ldots \ldots \ldots \ldots \ldots \ldots \ldots \ldots$ ] no

5. Have you smoked any cigarettes, cigars or a pipe?

[] No $\rightarrow$ [I I have never smoked [] I quit T HOWTHS OR YEARS ago

[] YES $\rightarrow$ a. How much did you smoke per day:

$$
\text { * cigarettes:___ * cigars:____ pipefuls: }
$$

b. When was the last time you. made a serious attempt to quit smoking? (IF MEVER. URITE "MEVER TRIED")

c. Do you want to quit smoking?

[1 NO

[1 YES $\rightarrow$ I want to quit within the next $\operatorname{month}(s)$ 
During the past wonth:

6. How many times a week did you usually eat (or drink) the following? (Each meal or snack - 1 time)

Red weat, such as beef, pork, or hamburger $\ldots \ldots \ldots \ldots \ldots \ldots \ldots \ldots$

Baked or broiled chicken or turkey

Fish Cheese (other than cottage cheese)

Cold cuts, hot dogs, bacon or sausage

Fried foods such as fried chicken, potato chips, french fries ......

Alcoholic beverages (beer, wine, or hard liquor)

Whole milk or ice cream (not nonfat or lowfat)

Fresh fruits and vegetables

Whole grain or oat bran cereal, muffins, pasta, or bread ...........

Pastry, cake, pie, donuts, or cookies.

7. About how many whole eggs (with yolks) did you usually eat a week? ...

8. When you drank alcoholic beverages, how many drinks did you usually have in one day? (If you didn't drink at all, write " $O^{\prime \prime}$ ) ............

9. How often did you do the following: $\frac{\text { ALWOST NLUAYS }}{1} \quad \frac{\text { OFTEH }}{2} \quad \frac{\text { SOMETIHES }}{3} \quad \frac{\text { MEVER }}{4}$

Put salt on or in your food? []

[]

[]

Put butter on your food, or eat food cooked in butter?

[1]

Put margarine on your food, or eat

food cooked in margarine or oil?

[1] [ ] [

Put mayonnaise, sour cream, or salad oil/dressing on your food?

Eat the skin on chicken or turkey?

Eat the fat on meat? [ []

During the past month:

10. At least once a week, did you engage in physical activities or exercise strenuously enough to make you work up a sweat or breathe hard? (e.g., jogging, calisthenics, swiming, bicycling, brisk walking, climbing stairs)

[] NO (SKIP TO QUESTION II) [] YES (AMSHER QUESTION IOA)

10A: List the types of exercise you regularly got, how long you usually spent doing each physical activity, and how many times a week you usually did it.

TYPE of PHISICU, NCTIUIII

1.

2.

3.
IIK. SPEIII

MIMUTES

MIKUTES

MINUTES
IIKSS PER VEER 
11. Ouring the past month were you taking blood pressure or heart medicine?

[] NO (SKIP TO QuEstion 28) []

12. If you took nitroglycerine pills: (SxIP TO QUESTION 23 IF NOT NPPLICABLE)
a. How often did you take them?
USURL I OF PILLS PER OAY:
OR USLU O OF PILLS PER VEEK: OTHER (DESCRIBE):

b. Did you take them when you had chest pains?

c. Did you take them before you exercised?

[] ALWAYS

[] ALWAYS

[] SOHETIMES

[1 SOMETIMES

1] NEVER

e. When else did you usually take them? (DEscribe)

[1] NEVER

13. How often did you have trouble remembering to take your medicines at the right times?

[1 ALtFAYS [] SOMETIMES [] NEvER

14. If you forgot to take your medicine at the right time, what did you usually do?

15. If you had any questions about your medicines or how they should be taken, did you talk with someone (e.g., your doctor or a nurse) to get the information you needed?
[] No
[] YES, MY DOCTOR
[] YES, A NURSE
[1 DIDN'I HAVE ANY QUESIIONS

16. This set of questions asks about how you have felt and how things were with you during the past month. For each question, please circle the one answer that comes closest to the way you have been feeling.

How much of the time:

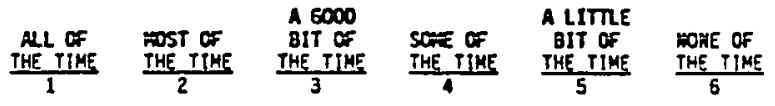

a. Did you feel a lot of stress in your work or personal 1 ife?

b. Were you a very nervous person?

c. Did you feel calm and peaceful?

d. Did you feel down-hearted and blue? ...................... 1

e. Were you a happy person? ....... 1

f. Did you feel so down in the dumps that nothing could cheer you up? 1

g. Did you act impatient or irritable toward those around you? ........

h. Were you worried about your health? .................. I

i. Were you afraid to do certain things because of your health? I

$\begin{array}{lllll}2 & 3 & 4 & 5 & 6 \\ 2 & 3 & 4 & 5 & 6 \\ 2 & 3 & 4 & 5 & 6 \\ 2 & 3 & 4 & 5 & 6 \\ 2 & 3 & 4 & 5 & 6 \\ 2 & 3 & 4 & 5 & 6 \\ 2 & 3 & 4 & 5 & 6 \\ 2 & 3 & 4 & 5 & 6 \\ 2 & 3 & 4 & 5 & 6\end{array}$


PASE .4

17. If you were employed outside the home during the month before your hospitalization, have you returned to work? (SXIP IF wot APPLICABLE)

[1 No $\rightarrow$ Are you planning to go back to work? [1 No [1 YES $\Rightarrow$ When?

[1 YES $\rightarrow$ On what date did you go back to work? How many hours a week are you working? Are you working at the same job? [1 No [] YES

18. Since your hospitalization, what kinds of changes have you made in your lifestyle to reduce your risk of having a heart attack?

19. Overall, how would you rate the cardiac education you received while in the Transitional Care Unit?
[] EXCELLENT
[1] GOOD
[] FAIR
[1] POOR

20. How helpful were the follow-up phone calls you recefved from the Carol Graham, the Cardiac Education Nurse?
VERY
FAIRLY
(] HELPFUL
SOMEWHAT
NOT AT AIR
[1 HELPFUI
(1) HELPFUL
[1 HELPFUI

21. Since your hospitalization (about three months ago):

a. How many times have you called Carol Graham (the Cardiac Education

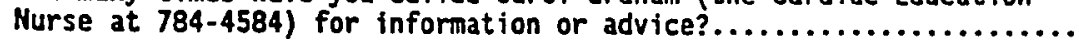
TIMES

b. How many times have you talked to your doctor or an Advice Nurse on information or advice related to chest pains or your heart condition? TIMES

c. How many times have you seen your doctor on an outpatient basis because of chest pain or heart trouble?

d. How many times have you been seen in the Emergency Room or Urgent because of chest pain or heart trouble? TIMES

22. Since your hospitalization, have you attended any of the following:

II "YOU GOTTA HAVE HEART" GARDIAC EDUCATION CLASS AT KAISER PERYANENTE-HAYWARD

(1) EXERCISE PROGRAY

[] CARDIAC/HEART EDUGATION CLASS AT:

1) STOP SMOKING PROGRAM

[] DIET OR CHOLESTEROL CLASS AT KAISER PERMANENTE

[] DIET OR CHOLESTEROL CLASS AT:

(1) STRESS MANAGEMENT PROGRAM

[] DEIGHT LOSS PROGRAY

I) CARDIAC REHAB: PROGRAM

$$
\text { AT: }
$$

[1 OTHER:

23. Did a spouse or significant other attend any of these programs with you?
[] No
[1 YES $\rightarrow$ Which programs? 
PACE 5

24. Do you want more information about programs or self-help materials to help you better understand heart disease and what you can do to improve your health?

[] No [] YES (DESCRIBE):

25. Additional coments or suggestions:

Thank you for your cooperation. Please return this questionnaire in the pre-addressed envelope enclosed. 
APPENDIX C

Photography Consent 


\section{KAISER}

DERMANENTE

MEDICAL CENTER

\section{PHOTOGRAPHY CONSENTS}

(Use Standard Consent Form (90440) For Clinical/Research Uses)

1. NEWS MEDIA: I hereby authorize Kaiser Foundation Hospitals. Kaiser Foundation Health Plan, Inc.. The Permanente Medical Group. inc., and the attending physicians to permit news media representatives to photograph, film, or videotape me or ___ (name of patient). who is my - (specify relationship), while under the care of the physicians and the hospital, and agree they may use, or permit others to use, the negatives. tapes. films. or prints, prepared therefrom. -

1 agree that the above named organizations, their employees, and agents, shall not be responsible in any way for the content of news media coverage in which the photography authorized herein is used.

DATE AND TIME

$\bar{n}$

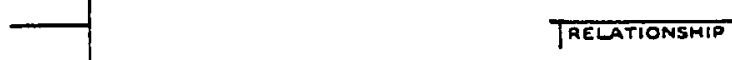

2. PUSLIC RELATIONS: I hereby certify to being over 18 years of age and authorize Kaiser Foundation Hospitals. Kaiser Foundation Health Plan, Inc., and The Permanente Medical Group. Inc., their personnel or contraetors, to photograph me or (name), who is my for the purposes described below for up to 10 years from the date of this release:

(specify relationship), and to use the negatives, tapes, films, or prints

PLEASE PRINT

Placed in Cardiac Education File.

Intended use oi photograph

Praced in Cardiac Education File.



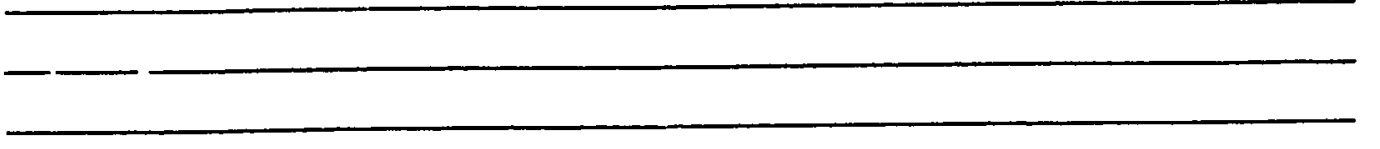

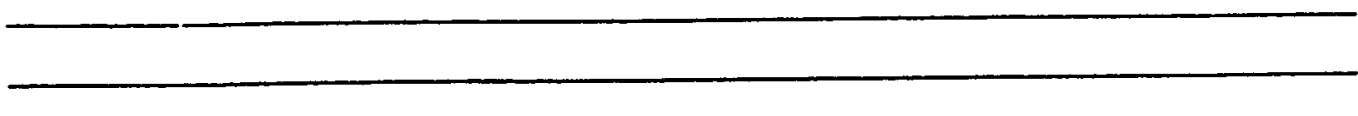

Name

Address

Telephone No.

\begin{tabular}{l|l|}
\hline DATE AND TIME & SIGNATURE \\
\hline WITNESS TO SIGNING & OTHER'S SIGNATUAE \\
\hline
\end{tabular}


APPENDIX D

Patient Progress Record 


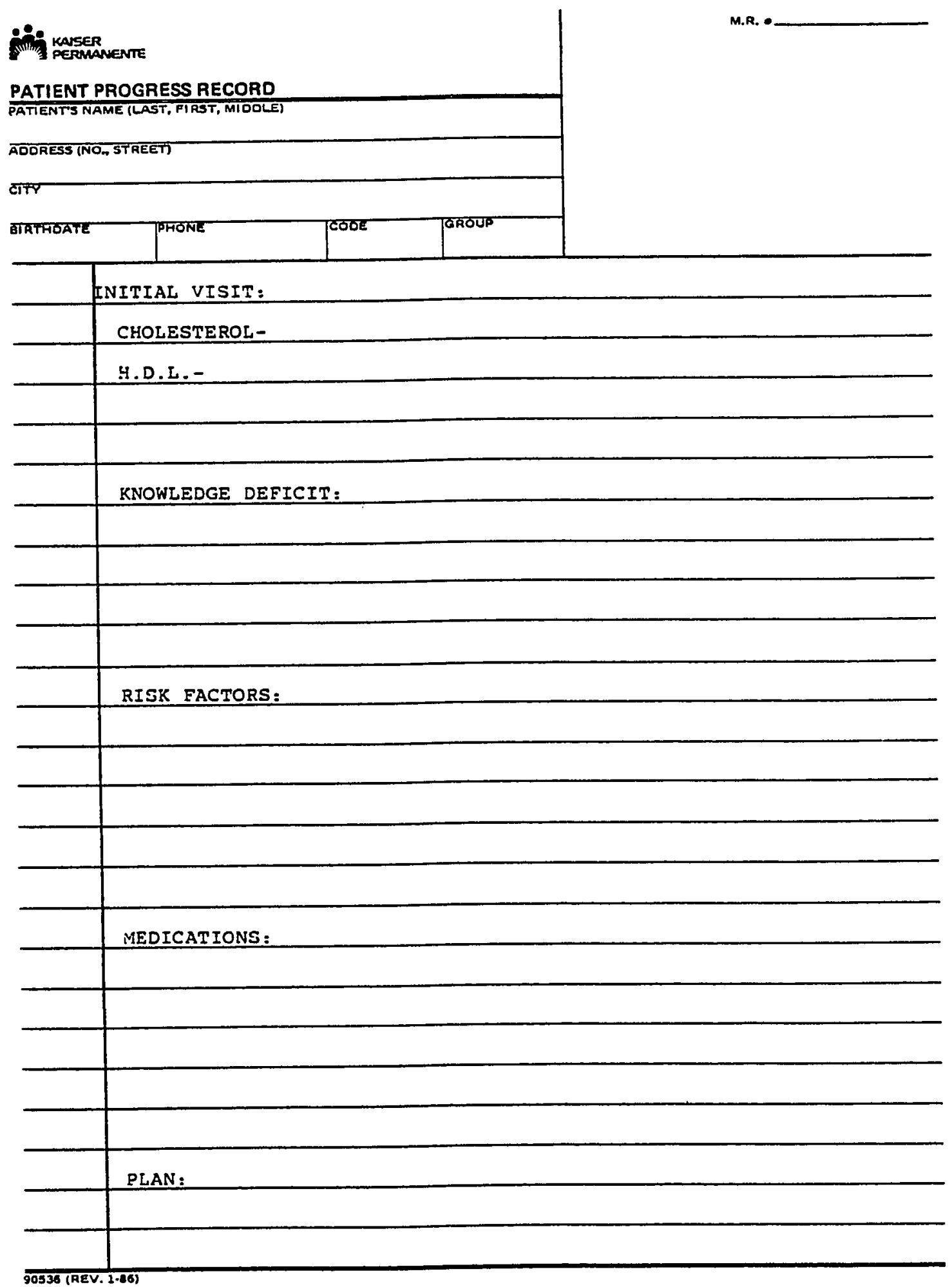




\section{PATIENT PROGRESS RECORD}

PATTENT'S NAME (LAST, FIRST, MIDOLE)

ADDRESS (NO.. STREET)

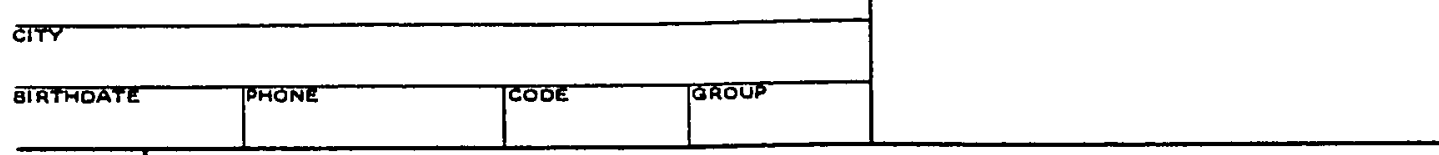

TELEPHONE CALL \# :

SMOKING :

\section{Are you smoking cigarettes?}

If "no" - When did you stop?

If "yes" - How many cigarettes a day?

Are you planning to stop?

When and how do you plan to stop?

DIET:

EXERCISE :

MEDICATION :

Have you found it necessary to phone your physician?

How many $t$ imes?

Reasons? 


\section{PATIENT PROGRESS RECORD}

PATIENT'S NAME (LAST, FIRST, MIOOLE)

AOORESS (NOA STREET)

हाग

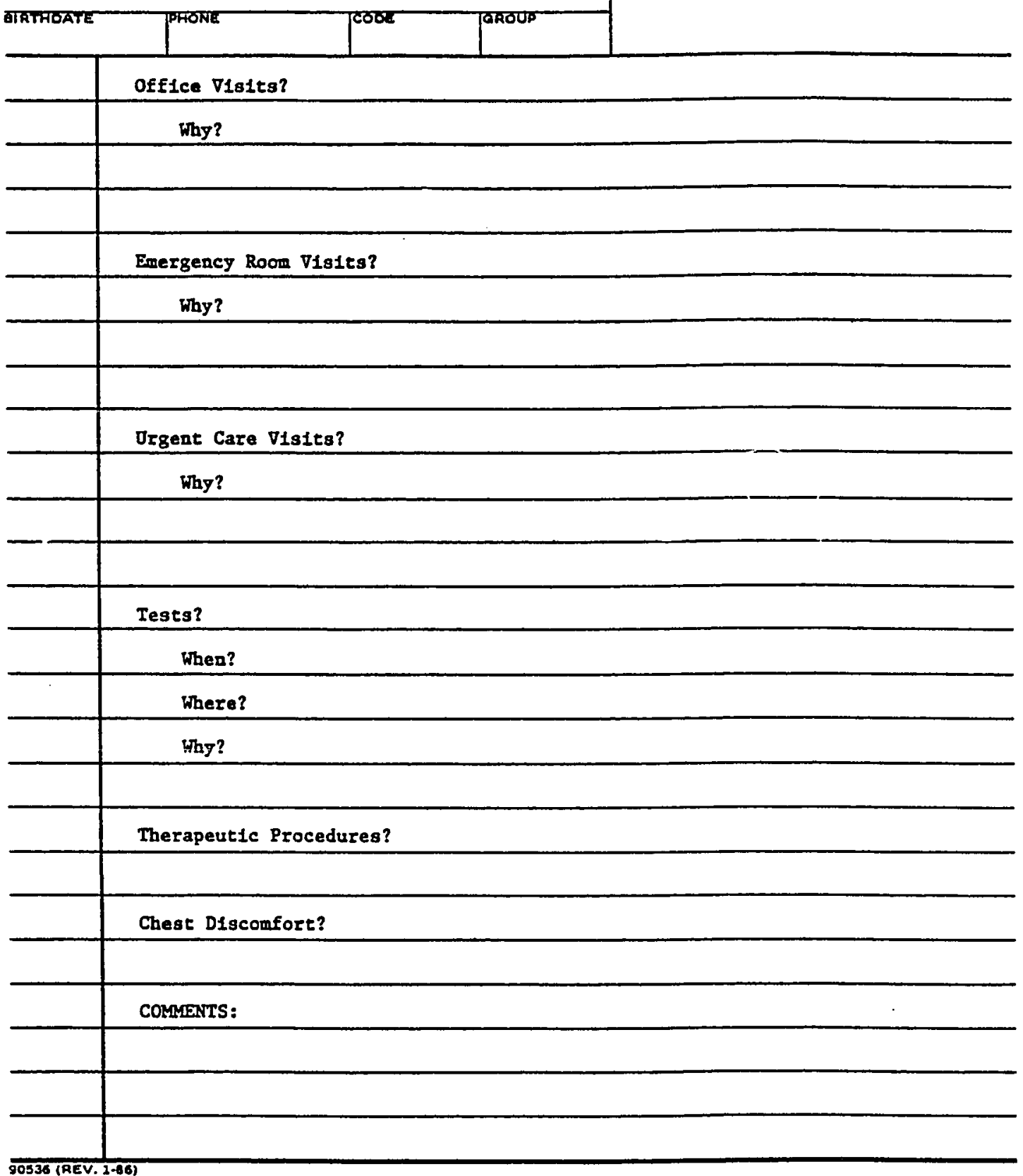




\section{APPENDIX E}

Human Subjects Institutions Review Board

Project Proposal Review 


\section{SAN JOSE STATE UNIVERSITY GRADUATE STUDIES AND RESEARCH \\ HUMAN SUBJECTS INSTITUTIONAL REVIEW BOARD PROJECT PROPOSAL REVIEW}

Regular Review

Expodited Review

Deadline Date

1, the undersigned member of the San Jose State University Human Subjects Institutional Review Board, have reviewed the following proposal submitted to the Board on by:

PRINCIPAL INVESTIGATOR: BARBARA IUSTIG

PROTOCOL\#: 7521 DEPT:

PROJECT TITLE: CARDIAC EDUCATION PROGRAM

Nursing

I recommend the following action (indicate one):

1. Approved for clearance as involving minimal risk to Human Subjects.

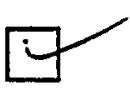

2. Approved for clearance with risk to Human Subjects.

3. Approval depends upon the satisfactory completion of the following conditions.

4. I have serious concerns about this protocol and it should go before the full committee to review.

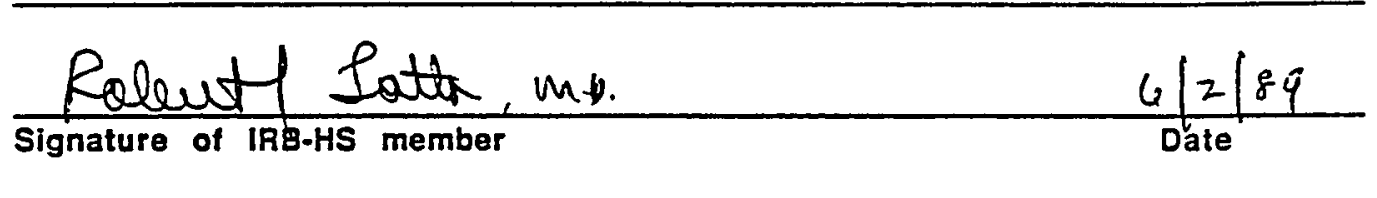

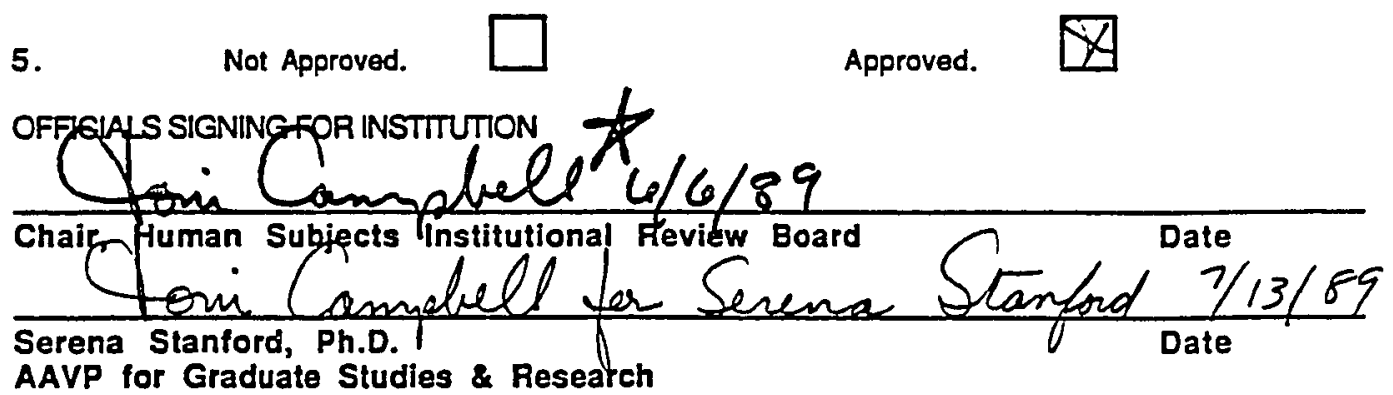

Please retum to: Graduate Studies and Research Office, Administration Building 150, San Jose State University, One Washington Square, San Jose, CA 95192-0139

(408) $924-2480$ 
APPENDIX F

Consent Forms 


\begin{tabular}{|c|c|}
\hline $\begin{array}{l}\text { Kaiser Permanente Medical Cenver } \\
27+\infty 0 \text { Hespenan Boulevard } \\
\text { Hatward. Califormia } 94545-1299 \\
\text { (tis) } 784-1000\end{array}$ & $\begin{array}{l}\text { Ivan L. Fandery } \\
\text { Administrator } \\
\text { Pani H. Jemeth, M.D. } \\
\text { Ptryician-in-Chief }\end{array}$ \\
\hline
\end{tabular}

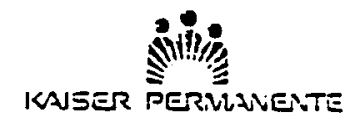

Ivan Fawley

Adolntstrator

Carol Nothern; RN

Assistant Adainistrator

Kaiser Hospital

27400 Hespertan Blvd.

Hayward, California 94545

Dear

Enclosed please find a copy of the research project I plan to conduct in the Transitional Care Unit in conjunction with our Cardlac Education Program. The educational program is in place, having started February 1, 1989. The research project will be implemented in August, 1989.

In order to comply with the regulations of the Human Subjects Review Board, it is necessary for me to have permission in writing from you for obtaintag information from patients. A consent form is also enclosed that would be given to all patients in the study--both experimental group and control group.

This is an ambitious study that has generated much enthuslasm and support from the phystcians, as well as other departments, including Health Center Education, Medical Office Nursing, Dietary, Social Services, and Pharmacy.

Thank you for your assistance in this study.

Sincerely yours,

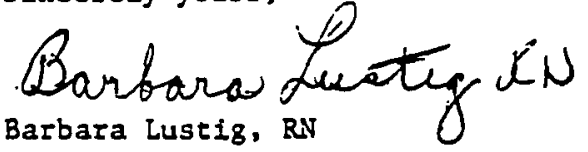

Superv1sor, TCU

CC: Human Subjects Review Board Paul Jewet, MD, P.I.C.

b1: Encl. 


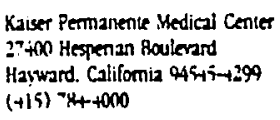

Kaiser Permanente Medicai Center

29 imo Hespenan Roulerand

Hasward. Cailiomia $945+17-4299$

$(+15)-4++000$

ivan L. Fawhey

Administrator

Pavil H. Jeweth, M.D.

Ptỵsteian-in-Chref

May 15, 1989

Barbara Lustig, R.N.

Supervisor, TCU

Kaiser Permanente Medical Center

27400 Hesperian Boulevard

Hayward, California 94545

Dear Barbara,

Ivan and I discussed your research project. He joins me in giving our consent to obtain information from patients for this study as long as you obtain their written consent by means of your consent Form.

Again, I commend you, Barbara, for embarking on the first Kaiser Permanente Nursing research study at Hayward.

Please let me know if I can be of any assistance.

sincerely,

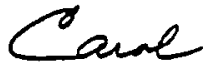

Carol Nothern, R.N.

Assistant Adrinistrator

$\mathrm{CN}: \mathrm{ea}$

CC: I. Fawley

P. Jewett, M.D.

Human Subjects Review Board 
July 18,1989

Barbara Lustig, RN

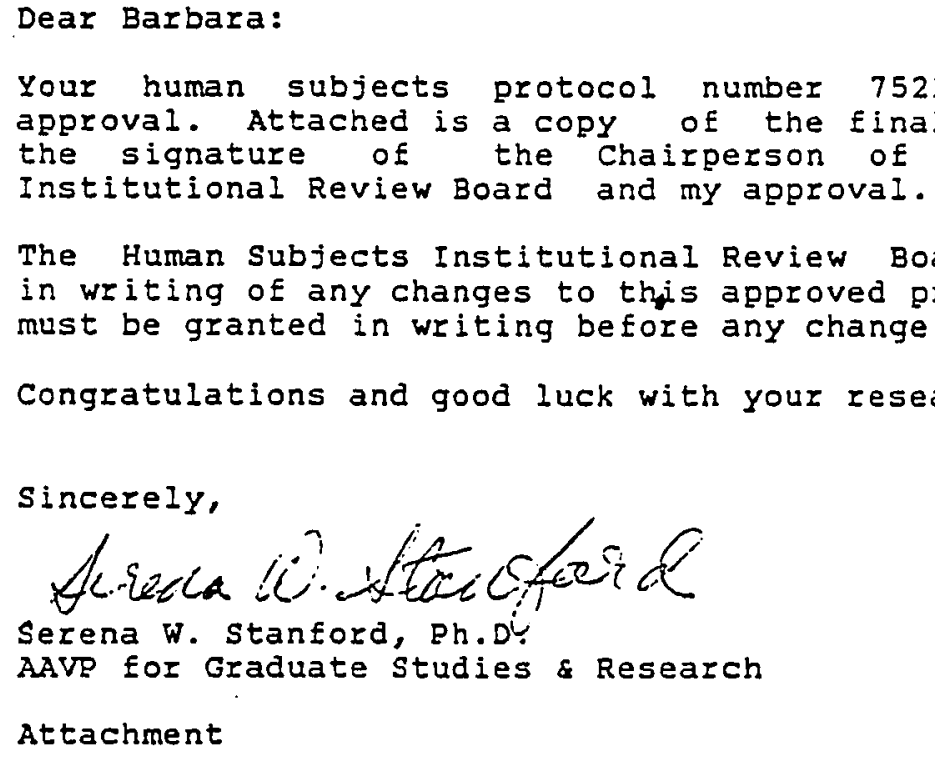

Sincerely,

Serena W. Stanford, Ph.Dí

AAVP for Graduate Studies \& Research

Attachment

The Human Subjects Institutional Review Board must be notified in writing of any changes to this approved protocol, and approval must be granted in writing before any change is instituted.

Congratulations and good luck with your research! 
APPENDIX G

Patient Consent Form 
Kaser Pemanente Medial Conve

27.400 Hepen is Boulenzd

Hasuzed Elifomia $945 ;-209$

$16: 5 ;, 78,+000$
Mn L Fanky

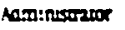

Paw H. Jewer. M.D.

Phrsocan-in-oud

CONSENT FORM
RASER PERMANENTE AGREEMENT TO PARTICIPATE IN RESEARCH AI RAISER HOSPITAL, HAYWARD,
RESPONSIBLE INVESIIGATOR:

IIILE OF PROTOCOL: CAROIAC EDUCATION AS A MEANS TO REDUCE RISK EACTORS

I have beez asked to partictpace in a research study that is investigating the effectivezess of a cardiac education program in recucing risik factors leading to heart disease. The results of this study should fur her our understanding of what means are available to reduce risk factors and Inprove qualic; of Iife.

I uncerssand that

(1) I will be asked to participace in elasses while in the hospital for a period of approxtmately 45 minutes each day.

(2) I will be expected to furnish Information to the Cardiac Educator Nurse on a regular basis botin in the hospital and by telepione from home.

(3) I understand there is not risk, discomfort, or inconventence to me in farticipating in this study.

(4) The possibie besefits are that I will increase my knowledge of cardias İsik fastozs, including diet, exerctse, stress reduction, and others.

(5) The results from this seudy way be published, but any information from bis study that can be identified with me will remain conitdential and will be disciosed only with my permission or as required by law.

(5) Any questions about my participation in this study will be asswered by Earbara Listig, RY, Supv. ICU Pinone: $115-784-4671$

Conpiaints about the prograr may be presented to Sharon wainl, PhD.

Phone: 4E8 - 924-3156. For questions or complaints atout research subject's Ifgirs, $0=$ in tie evert of research-relared infury, concaci Sezeza Stanford, $\mathrm{Ph} . \mathrm{D}$. (Associate Academic $\nabla$ ice President for Graduate Studies \& Research at San Jose State University) at $408-924-2480$.

(7) My consent is given voluntarily without being coerced; I may refuse to participate in this study or in any part of this study, and I may withdraw at any t1me, without prejudice to my relations with Raiser Permaneate Medical Cencez.

(8) I have recefved a copy of thus consent form for my ffle.

I HAVE MADE A DECISION WHETHER OR NOT IO PARTICIPATE. MY SIGNATURE INDICATES THAI I UAVE READ THE INFORYAIION PROVIDED ABOVE AND THAT I RAVE DECIDED TO PARTICIPATE.

Subject's Signature Investigator's Signature

Date: 


\section{APPENDIX $\mathrm{H}$}

\section{Cardiac Education Program Form}


Address: जनहताल बाग ZIP

Phone Na: MOME WORK

Primary Physician:

Admission Date: Diagnosis:

I. Risk Factors Identified:

1.

3.

II. Packet Received:

Date:

III. Circle Classes Attended:

1 Nutrition

2 Pharmacology

3 Risk Factors

4 Psychological Reactions

IV. Physical Therapy Program:

V. Circle Videos seen:
1 "High Blood Pressure"
2 "Stress Reduction
3 "Quit for Life"
4 "Freedom from Fat"
5 "Cholesterol"
6 "Signals for Action"
7 "Bypass, Story of a Patient

PATIENT/FAMILY EDUCATION

2.

$-4$.

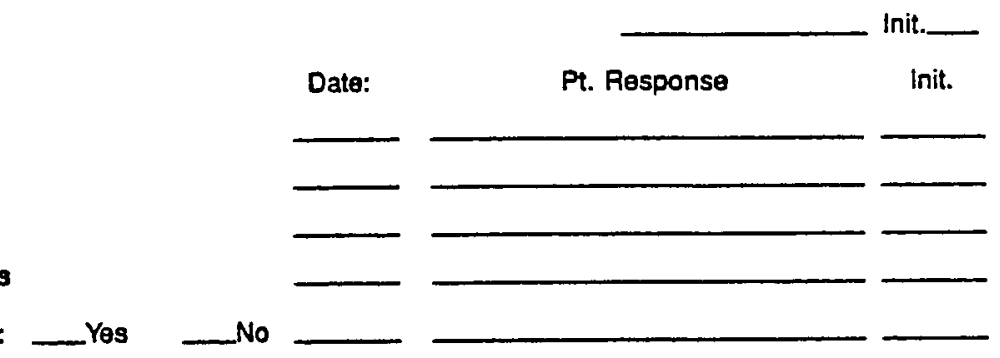

8 "Psychological Reactions to Heart Disease"

9 "Your Heart Attack and your Future"

10 "Your Prescription for Health"

11 "Move Into Action"

12 "Angina"

13 "Quit for Life"

14 Other (name)

Pt. Response: Init.

DISCHARGE PLAN

I. Diet Reviewed: Date

Pt. Response Init

II. Meds. Reviewed: Date

Pt. Responso Init.

III. Home exercise program reviewed: Date

Specity

IV. Referred to Health Education Center for outpatient classes: (please circle)

1 Stress Reduction

1 Stop Smoking

3 Cholesterol
4 "You Gotta Have Heart"

5 Woight Roduction

6 Other (name)

Nurse Signature 


\section{APPENDIX I}

Telephone Protocol 
Telephone Protocol

Patients will be called at home on the 5th and 10th day, 4 weeks, 3 months, and 6 months after discharge from the hospital.

Nurse will introduce herself and proceed with the following questions:

1. For smokers:

a. Are you smoking cigarettes?

b. If no, when did you stop?

c. If yes, how many cigarettes a day?

d. Are you planning to stop?

e. When and how do you plan to stop?

Encourage patient to enroll in the Health Education Center Stop Smoking Classes. Tell patient the dates and times. Offer to enroll patient. Discuss hazards of smoking and effects on cardiovascular system.

2. What did you eat today? Do you feel these are heart healthy foods?

Discuss a healthy diet. Remind patient of classes on lowering cholesterol. Talk about foods low in cholesterol and fat. Ask if patient has read his pamphlets on a healthy diet. Give patient recommendations for cookbooks specific for heart patients. Encourage patient to include soluble fiber, such as oat bran, apples, grapefruit, carrots, and metamucil in his diet.

3. How is your exercise program coming along?

Refer to patient's baseline questionnaire and ask specific questions according to the individual program patient has set up.

4. Are you taking your prescribed medications? Are you missing any doses or times? Which ones? Why? Refer to patient's discharge summary and be certain that the stated medications are the same as those prescribed. Have patient recite times. Ask if patient knows what each medication is prescribed for. Clear up any misunderstandings and if there is a serious problem, check with patient's physician. 
for. Clear up any misunderstandings and if there is a serious problem, check with patient's physician.

5. Have you found it necessary to telephone your physician? How many times did you call? For what reasons? Did you need to go in for a visit? If yes, why and to whom did you speak? Find out if patient was satisfied with the response received.

6. Have you needed to call the Emergency Department or Urgent Care? If yes, for what reason? Did you need to come in? For what reason?

Find out if patient was satisfied with the response he or she received. Discuss with patient the symptoms of an MI. Have patient recite emergency measures to be taken in the event of serious illness or a suspected MI.

7. Have you been experiencing any chest discomfort? Let patient describe if yes. Do you think it was angina? How long did it last? What did you do for it? How many episodes of pain have you had. Over a day? Over a week? (If patient took nitroglycerine, ask how many and at what time intervals; ask what activity brought on the angina pain).

8. Have you had any cardiac tests (e.g., Treadmill, Holter, Echo, EKG, Cath.)? Ask when, where, and results.

9. Have you had any therapeutic procedures (e.g., angioplasty, bypass surgery)?

10. At the end of the conversation, write your overall impression of how you perceive the patient to be doing. Note whether patient stated whether or not he felt better, and if he felt motivated to continue the program. 